\title{
Application of a two-step approach for mapping ice thickness to various glacier types on Svalbard
}

\author{
Johannes Jakob Fürst ${ }^{1}$, Fabien Gillet-Chaulet ${ }^{2}$, Toby J. Benham ${ }^{3}$, Julian A. Dowdeswell ${ }^{3}$, Mariusz Grabiec ${ }^{4}$, \\ Francisco Navarro ${ }^{5}$, Rickard Pettersson ${ }^{6}$, Geir Moholdt ${ }^{7}$, Christopher Nuth ${ }^{8}$, Björn Sass ${ }^{1}$, Kjetil Aas ${ }^{8}$, \\ Xavier Fettweis $^{9}$, Charlotte Lang ${ }^{9}$, Thorsten Seehaus ${ }^{1}$, and Matthias Braun ${ }^{1}$ \\ ${ }^{1}$ Institute of Geography, University of Erlangen-Nuremberg, Wetterkreuz 15, 91058 Erlangen, Germany \\ ${ }^{2}$ University of Grenoble Alpes, CNRS, IRD, Institut des Géosciences de l'Environnement (IGE), CS 40700 Grenoble, France \\ ${ }^{3}$ Scott Polar Research Institute, University of Cambridge, Lensfield Road, Cambridge CB2 1ER, UK \\ ${ }^{4}$ Faculty of Earth Sciences, University of Silesia in Katowice, ul. Bankowa 12, 40-007 Katowice, Poland \\ ${ }^{5}$ Departamento de Matemática Aplicada a las Tecnologías de la Información y las Comunicaciones, desp. A302-4, ETSI de \\ Telecomunicación, Universidad Politécnica de Madrid, Av. Complutense 30, 28040 Madrid, Spain \\ ${ }^{6}$ Department of Earth Sciences, Uppsala University, Geocentrum, Villav. 16, 75236 Uppsala, Sweden \\ ${ }^{7}$ Norwegian Polar Institute, Fram Centre, P.O. Box 6606 Langnes, 9296 Troms $\varnothing$, Norway \\ ${ }^{8}$ Department of Geosciences, University of Oslo, P.O. Box 1047, Blindern, 0316 Oslo, Norway \\ ${ }^{9}$ Department of Geography, University of Liège, Quartier Village 4, Clos mercator 3, 4000 Liège, Belgium
}

Correspondence to: Johannes Jakob Fürst (johannes.fuerst@fau.de)

Received: 1 March 2017 - Discussion started: 17 March 2017

Revised: 13 July 2017 - Accepted: 14 July 2017 - Published: 1 September 2017

\begin{abstract}
The basal topography is largely unknown beneath most glaciers and ice caps, and many attempts have been made to estimate a thickness field from other more accessible information at the surface. Here, we present a two-step reconstruction approach for ice thickness that solves mass conservation over single or several connected drainage basins. The approach is applied to a variety of test geometries with abundant thickness measurements including marine- and landterminating glaciers as well as a $2400 \mathrm{~km}^{2}$ ice cap on Svalbard. The input requirements are kept to a minimum for the first step. In this step, a geometrically controlled, non-local flux solution is converted into thickness values relying on the shallow ice approximation (SIA). In a second step, the thickness field is updated along fast-flowing glacier trunks on the basis of velocity observations. Both steps account for available thickness measurements. Each thickness field is presented together with an error-estimate map based on a formal propagation of input uncertainties. These error estimates point out that the thickness field is least constrained near ice divides or in other stagnant areas. Withholding a share of the
\end{abstract}

thickness measurements, error estimates tend to overestimate mismatch values in a median sense. We also have to accept an aggregate uncertainty of at least $25 \%$ in the reconstructed thickness field for glaciers with very sparse or no observations. For Vestfonna ice cap (VIC), a previous ice volume estimate based on the same measurement record as used here has to be corrected upward by $22 \%$. We also find that a $13 \%$ area fraction of the ice cap is in fact grounded below sea level. The former $5 \%$ estimate from a direct measurement interpolation exceeds an aggregate maximum range of 6-23\% as inferred from the error estimates here.

\section{Introduction}

For the 210000 glaciers and ice caps on this planet (Bishop et al., 2004), satellite remote sensing based on optical or radar instruments enables us to monitor glacier surface geometry (e.g. Farr et al., 2007; Tachikawa et al., 2011) and glacier extent variations (e.g. Raup et al., 2007; Rankl et al., 
2014). Recent studies have shown that surface elevation changes can be produced on a regional basis (e.g. Berthier et al., 2010; Zwally et al., 2011; Gardelle et al., 2013; Paul et al., 2015; Zwally et al., 2015; Rankl and Braun, 2016; Vijay and Braun, 2016). However, for the majority of these ice geometries, there is no information on ice thickness (GärtnerRoer et al., 2014, 2016). Any attempt to predict the glacier demise under climatic warming and to estimate the future contribution to sea-level rise (Radić and Hock, 2011; Radić et al., 2014; Marzeion et al., 2012, 2014; Huss and Hock, 2015) is limited as long as the glacier thickness is not well known. Moreover, the ignorance of the bed topography inhibits the applicability of ice-flow models, which could help to understand dominant processes controlling the ice-front evolution of marine-terminating glaciers. This is because the basal topography exerts a major control on the dynamic response of grounded ice (Schoof, 2007, 2010; Favier et al., 2014). A reason for further concern is that grounded parts of the Antarctic Ice Sheet are assumed to respond to climatic warming primarily by outlet glacier acceleration as the floating ice shelves thin (Paolo et al., 2015) and lose their buttressing ability (Fürst et al., 2016). As it is impractical to measure ice thickness for most glaciers, reconstruction approaches that can infer thickness fields from available geometric, climatic and ice-velocity information have been proposed.

In terms of input requirements, reconstruction approaches always need information on the geometric setting. This normally comprises the glacier outline and the surface topography. In the Ice Thickness Models Intercomparison eXperiment (Farinotti et al., 2016), two types of reconstruction approaches rely exclusively on this geometric information. The first type assumes perfect plasticity, relating ice thickness to a glacier-specific yield stress, which itself is inferred from the elevation range of the glacier (Linsbauer et al., 2012; Frey et al., 2014; Carrivick et al., 2016). The second type assumes that characteristics of the ice-covered bed topography resemble the nearby ice-free landscape (Clarke et al., 2009). Under this premise, an artificial neural network is trained with digital elevation models (DEMs) of the surrounding area. Another reconstruction approach (Gantayat et al., 2014) uses additional information on surface velocities and it relies on the shallow ice approximation (SIA; Hutter, 1983; Morland, 1986). Under this assumption, surface velocities directly translate into ice-thickness values dependent on glacier-surface slopes. Most of the participating approaches rely, however, on mass conservation. This implies that they need information on the difference between the actual surface mass balance (SMB) and the contemporaneous surface elevation changes. This difference is referred to as the apparent mass balance (AMB; Farinotti et al., 2009b). A large subset of the mass-conserving approaches assumes a generic AMB informed by the geographic location and the continental character of the prevailing climate (Farinotti et al., 2009a; Huss and Farinotti, 2012; Clarke et al., 2013). In addition, these approaches rely on the SIA and require an input icedischarge value for marine-terminating glaciers. As standard procedure, many of the above approaches dissect glacier outlines into a number of centrelines along which the actual reconstruction is performed. Consequently, these approaches are computationally efficient but they require a final interpolation of the thickness values between these centrelines. To avoid such an interpolation, other mass-conservation approaches determine a solution over entire glacier basins (Morlighem et al., 2011; McNabb et al., 2012; Brinkerhoff et al., 2016) at the expense of computational costs. Two strategies are pursued for these reconstruction types. For the one type, ice-flow models are applied in a pseudo-transient way such that the actual surface elevation remains close to observations optimising the bed topography (van Pelt et al., 2013). For the other type, ice velocities are taken from observations and enter the mass-conservation equation, which is then directly solved for ice thickness (Morlighem et al., 2011; McNabb et al., 2012; Mosbeux et al., 2016).

From an observational perspective, operational and regular satellite imagery acquisition and processing has become an indispensable and continuously growing source of information. Therefore, automated procedures have been brought in place providing products such as glacier outlines (Bishop et al., 2004; Atwood et al., 2010; Nuth et al., 2013; Rankl et al., 2014; Paul et al., 2015), digital elevation models (ArcticDEM, http://pgc.umn.edu/arcticdem; ASTER GDEM2, https://asterweb.jpl.nasa.gov/gdem.asp; Tachikawa et al., 2011; SRTM, http://www2.jpl.nasa.gov/ srtm/; Farr et al., 2007; TanDEM-X, http://www.dlr.de/eo/en/ desktopdefault.aspx/tabid-5727/10086_read-21046/; Rankl and Braun, 2016) and surface velocities (Joughin et al., 2010; Rignot et al., 2011; Rignot and Mouginot, 2012; Rankl et al., 2014; Rosenau et al., 2015; Seehaus et al., 2015; Fahnestock et al., 2016; Seehaus et al., 2016). Surface elevation changes can be inferred from DEM differencing. Much development effort is put into reducing DEM uncertainties associated with signal penetration and not-well-known firn properties (e.g. Gardelle et al., 2012; Berthier et al., 2016). Depending on the mission, surface elevation changes can be generated almost operationally for large areas (Gardelle et al., 2013; Rankl and Braun, 2016). Concerning surface velocities from remote sensing, a good coverage is challenging in areas where displacements are small, where the glacier surface is featureless or during periods of rapid changes in surface characteristics. Moreover, associated uncertainties generally exceed $10 \mathrm{~m} \mathrm{yr}^{-1}$ (e.g. Seehaus et al., 2015; Schwaizer, 2016), which limits the reliability in slow-moving areas. The SMB field is another prerequisite for mass conservation. It is not directly measurable by remote sensing techniques. Sparse SMB records can be used to determine elevation gradients that are then extrapolated according to a regional DEM (Farinotti et al., 2009b). Otherwise, SMB records are exploited to validate parametric SMB approaches (Möller et al., 2016) or more complex regional climate mod- 
els (Lang et al., 2015; Aas et al., 2016). For ice-thickness measurements, a standardised, open-access database has recently been launched (Gärtner-Roer et al., 2014), and its gradual growth already justified an updated release (GärtnerRoer et al., 2016). Despite this international effort, many thickness measurements still remain unpublished.

In light of the continuously growing body of information, it becomes easier to gather the input fields for sophisticated thickness-reconstruction approaches. In this regard, we present a two-step approach that provides a physically based thickness field over entire glacier basins, ice fields or ice caps. The first step has limited input requirements (Sect. 2.2). In the second step, additional velocity information is exploited to update and improve the thickness reconstruction in specific areas (Sect. 2.3). A final interpolation of the basal topography is not required. For a set of three test geometries on Svalbard, the necessary input data were gathered (Sect. 3) and thickness maps are inferred (Sect. 4). A rich thickness record is available on these test glaciers and serves to constrain both the ice-thickness distribution and the associated map of error estimates.

\section{Methods}

The thickness-reconstruction approach is based on mass conservation and largely originates from ideas presented in Morlighem et al. (2011). We opted for a two-step approach because surface velocity information from satellite remote sensing often fails to cover entire drainage basins. In the first step, an ice flux is calculated from the difference between SMB and surface elevation changes. The flux solution is translated into a glacier-wide thickness field assuming the SIA (Hutter, 1983). In the second step, the thickness field is updated in areas with reliable velocity information.

\subsection{Mass conservation}

Over the ice-covered domain $\Omega$, the material incompressibility can be written as follows (p. 333 in Cuffey and Paterson, 2010):

$$
\frac{\partial H}{\partial t}+\nabla \cdot(\boldsymbol{u} H)=\dot{b}_{\mathrm{s}}+\dot{b}_{\mathrm{b}} .
$$

Here, $\nabla \cdot$ is the divergence operator in two dimensions, $H$ is the ice thickness, $\boldsymbol{u}=\left(u_{1}, u_{2}\right)$ are the vertically averaged, horizontal velocity components and $\partial H / \partial t$ are temporal surface elevation changes. Surface and basal mass balance are denoted with $\dot{b}_{\mathrm{s}}$ and $\dot{b}_{\mathrm{b}}$, respectively. The flux divergence $\boldsymbol{\nabla} \cdot \boldsymbol{F}=\boldsymbol{\nabla} \cdot \boldsymbol{u} H$ is unknown a priori and we rearrange accordingly.

$\nabla \cdot \boldsymbol{F}=\dot{a}$

All source and sink terms are combined in the apparent mass balance field $\dot{a}=\dot{b}_{\mathrm{s}}+\dot{b}_{\mathrm{b}}-\partial H / \partial t$. Throughout this manuscript, we assume that the basal mass balance $\dot{b}_{\mathrm{b}}$ is negligible.

\subsection{First step: flux-based solution}

In a first step, the mass conservation (Eq. 2) is solved for the ice flux $\boldsymbol{F}$ (Sect. 2.2.2) while prescribing the flux direction (Sect. 2.2.1). The flux solution is translated into a glacierwide thickness field relying on the SIA (Sect. 2.2.4). In a last step, the error associated with the thickness reconstruction is estimated (Sect. 2.2.5).

\subsubsection{Flux direction}

With prior knowledge only on $\dot{a}$, the single massconservation equation is insufficient to determine the two unknown flux components. To close the system, ice flux is separated into its magnitude $F$ and its direction vector $\boldsymbol{r}$.

$\boldsymbol{F}=F \cdot \boldsymbol{r}$

The direction is specified following Brinkerhoff and Johnson (2015) as the solution to

$\boldsymbol{\tau}_{\mathrm{s}}=\nabla\left[(l \cdot H)^{2} \nabla \cdot \boldsymbol{\tau}_{\mathrm{s}}\right]+\boldsymbol{\tau}_{\mathrm{d}}$.

Here, $\boldsymbol{\tau}_{\mathrm{s}}$ is a smoothed version of the driving stress $\boldsymbol{\tau}_{\mathrm{d}}=(\rho g) \cdot H \cdot \nabla h$. Other parameters needing specification include the ice density $\rho=917 \mathrm{~kg} \mathrm{~m}^{-3}$, the gravitational acceleration $g=9.18 \mathrm{~m} \mathrm{~s}^{-2}$ and the surface elevation $h$. The flux direction vector $\boldsymbol{r}$ is computed by normalising $\boldsymbol{\tau}_{\mathrm{s}}$. Along the lateral glacier margin $\Gamma$, the following boundary condition is set:

$\left(\nabla \cdot \boldsymbol{\tau}_{\mathrm{s}}\right) \cdot \boldsymbol{n}_{\Gamma}=0$.

Here, $\boldsymbol{n}_{\Gamma}$ is perpendicular to $\Gamma$. The solution to Eq. (4) is equivalent to an averaging of the driving stress using a variable length scale $(l H)$. This scaling stems from theoretical work on the influence of longitudinal stress gradients on glacier flow (Kamb and Echelmeyer, 1986). These stress gradients are comparable to membrane stresses in thin body mechanics (Hindmarsh, 2006). Membrane stresses can instantly transmit perturbations upglacier but this transmission was shown to be a secondary factor in terms of centennial ice-sheet volume evolution (Fürst et al., 2013). The associated scaling length is usually expressed as a multiple $l$ of the ice thickness $H$. For $l=10$, we find that resultant flux streamlines are inappropriately averaged over adjacent branches of a single valley glacier. For $l=1$ however, the routing remained locally defined. We therefore decided to prescribe $l=3$, in agreement with the suggestion by Kamb and Echelmeyer (1986), who expected coupling lengths for valley glaciers between $l=1$ and $l=3$.

By construction, the ice thickness is a priori unknown and so is the coupling length scale $(l H)$. Therefore, we assume 
$H=100 \mathrm{~m}$ to compute an initial flux direction field $\boldsymbol{r}$. Then, a first estimate is available for the thickness field and flux directions are updated accordingly. Thereafter, directions are kept fixed during the optimisation (Sect. 2.2.3). The reasons for prescribing the direction are to limit the degrees of freedom during the optimisation and because the first-step thickness field already captures the general magnitude of the observations giving reasonable coupling length $(l H)$.

\subsubsection{Flux magnitude}

To determine the flux magnitude $F$ according to Eqs. (2) and (3), we use the Elmer finite-element software developed at the Center for Science in Finland (CSC-IT, http://www. csc.fi/elmer/) and more specifically the mass-conservation solver implemented in its glaciological extension Elmer/Ice (Gagliardini and Zwinger, 2008; Gillet-Chaulet et al., 2012; Gagliardini et al., 2013). For the discretisation of the problem, we select the stabilised streamline-upwind PetrovGalerkin (SUPG) scheme (Brooks and Hughes, 1982). Along all land-terminating segments of the glacier outline, we impose a zero-flux condition. A free boundary condition is chosen across marine ice fronts, providing an ice-discharge estimate consistent with the AMB. Inflow boundaries did not occur in our setup. These would require Dirichlet conditions on the ice flux.

\subsubsection{Cost function and single-variate optimisation}

The direct flux solution to all input fields often shows widespread negative values and high spatial variability. Therefore, we chose to iteratively update the AMB-field $\dot{a}$, as a control variable, such that undesired characteristics in the flux field are reduced. We anticipate that the flux magnitude $F$ is positive and smooth. For the purpose of the iterative optimisation, we introduce the following cost function $J$.

$$
\begin{aligned}
J & =\lambda_{\text {pos }} \cdot \int_{\Omega} F^{2} \cdot H[-F] d \Omega+\lambda_{\text {reg }} \cdot \int_{\Omega}\left(\frac{\partial F}{\partial x}\right)^{2} \\
& +\left(\frac{\partial F}{\partial y}\right)^{2} d \Omega+\lambda_{\dot{a}} \cdot \int_{\Omega}\left(\dot{a}-\dot{a}^{\text {init }}\right)^{2} d \Omega
\end{aligned}
$$

Here, $H[\mathrm{~s}]$ is the Heaviside function, being 0 for negative and 1 for positive $s \in \mathbb{R}$. The first term is thus 0 for positive flux values but penalises negative flux solutions. The second term is a regularisation, which favours smooth flux solutions. The last term adds up differences between the iteratively updated $\dot{a}$ and the initial input $\dot{a}^{\text {init }}$. The cost $J$ should primarily be considered as a function of $\dot{a}$. As the AMB is iteratively updated, the cost should decrease. Multiplier values are $\lambda_{\text {pos }}=10^{2}, \lambda_{\text {reg }}=10^{1}$ and $\lambda_{\dot{a}}=10^{-2}$. For Werenskioldbreen (WSB), we chose $\lambda_{\text {reg }}=10^{0}$ to compensate for resolution differences. The multiplier choice aimed at a balance between improving the smoothness of the flux field and reduc- ing areas with negative flux values by adapting $\lambda_{\text {pos }}$ and $\lambda_{\text {reg }}$. The solution showed little sensitivity to changes in $\lambda_{\dot{a}}$.

For the optimisation of the cost function, we rely on the "m1qn3" module (Gilbert and Lemaréchal, 1989) that can solve large-scale unconstrained minimisation problems. It requires first derivatives of the cost with respect to the single control variables $\dot{a}$. For a precise calculation of these derivatives, we rely on the adjoint system associated with Eq. (2). The stopping criterion for the iterative optimisation is nondimensional at $10^{-14}$ and computed as a ratio between the current and the initial norm of the cost derivatives.

\subsubsection{Inferring ice thickness}

Once a flux field is determined over the glacier domain, the ice thickness is inferred in a post-processing step. Flux values are locally translated into thickness values assuming the SIA (Hutter, 1983).

$F^{*}=\frac{2}{n+2} B^{-n}(\rho g)^{n}\|\nabla h\|^{n} \cdot H^{n+2}$

Here, the flow law exponent is $n=3$ and the superscript * denotes a flux correction (see below and Appendix C3). Note that, in this way, the first-step reconstruction neglects effects from basal sliding, which limits its applicability to areas of slow ice flow. The SIA is typically applied to geometries with small aspect ratios (vertical vs. horizontal scales), which is not necessarily the case for our test geometries. Accounting for the influence of membrane stresses on ice flow, we correct the local surface slope magnitude $\|\nabla h\|$ informed by the smoothed driving stress $\boldsymbol{\tau}_{\mathrm{s}}$ (Eq. 4), assuming $\left\|\boldsymbol{\tau}_{\mathrm{s}}\right\|=(\rho g) H \cdot\|\nabla h\|$. In areas near the ice divide, surface slopes can locally become very small and thickness values diverge. Therefore, we decided to impose a slope threshold $\alpha_{0}=1^{\circ}$ as a lower limit on $\nabla h$. The chosen threshold is small as compared to other reconstruction approaches. For a similar reconstruction approach, combining mass conservation with the SIA along glacier flow lines, Farinotti et al. (2009b) apply a $5^{\circ}$ limit. Assuming perfect plasticity to infer glacier thickness in Patagonia, Carrivick et al. (2016) set a lower limit of $1.7^{\circ}$. Even though our choice for $\alpha_{0}$ is somewhat lower, the limit is still applied over a $17 \%$ area fraction of the Vestfonna ice cap (VIC) test geometry (Sect. 3). For the 1.7 and $5^{\circ}$ limits, this area fraction increases to 46 and $94 \%$, respectively.

The ice-viscosity parameter $B$ is unknown a priori. Yet, where thickness measurements are available, $B$ can be computed from Eq. (7). Thereafter, the scattered information on $B$ is interpolated over the entire glacier domain. To avoid unreliable extrapolation effects, we prescribe a mean $B$ value from all measurements around the lateral domain margin. If no thickness measurements were available, an a priori choice of the viscosity parameter $B$ is required.

We apply a correction to the flux solution before computing the ice thickness from Eq. (7). Details of this flux 
correction and the sensitivity of the results are given in Appendix C3. The reason is that despite the cost term on negative ice flux (Sect. 2.2.3), negative values prevail in limited areas, which transmit into the thickness field. When the AMB $\dot{a}$ shows only few source areas with net accumulation, ice flux remains small and negative values were found over as much as $5 \%$ of one test glacier. Zero transitions in the flux solution directly transmit into the ice-thickness field. To prevent such spurious variations, we correct the flux solution according to Eq. (C1), which guarantees positive flux. In areas of more pronounced ice flux, where the correction is not necessary a priori, its effect is inherently compensated by adapting the viscosity parameter $B$ where thickness measurements were collected. If no thickness measurements are available, inferred thickness values are reduced by at most $2 \%$ for pronounced ice flow.

\subsubsection{Formal error estimate}

Together with the thickness map, we present a formal error map. For this purpose, the uncertainty of the input fields, i.e. the SMB and $\partial H / \partial t$, are propagated in two steps. Uncertainties are first transmitted through the mass-conservation equation (Eq. 2), and the resulting estimate of the flux error is then scaled by a SIA flux-thickness conversion (Eq. 7). For the first step, we follow the ideas presented in Morlighem et al. (2014), who assume that the inaccurate flux field $F+\delta F$ also satisfies mass conservation.

$\nabla \cdot[(F+\delta F) \cdot(\boldsymbol{r}+\delta \boldsymbol{r})]=\dot{a}+\delta \dot{a}$

Here, $\delta \dot{a}$ is the uncertainty of the AMB and $\delta \boldsymbol{r}$ is the error on the prescribed flux direction. Neglecting second order terms and accounting for the fact that $F$ satisfies Eq. (2), the flux error is a solution of

$\nabla \cdot\left[\boldsymbol{r} \delta F_{1}\right]=\|\delta \dot{a}-\nabla \cdot[F \delta \boldsymbol{r}]\|$.

Along the land-terminating domain margin, we assume zero flux and the thickness error estimate implicitly becomes zero. At the thickness measurement locations, we assume that the ice flux is known with a precision that is equivalent to the uncertainty in the thickness measurements $\delta H_{\mathrm{obs}}$. The thickness-measurement uncertainty is translated into a fluxequivalent value using Eq. (7) without the flux correction. The solution to Eq. (9) shows a sawtooth pattern along the ice flow, as error estimates increase downglacier until another measurement is reached. There the value drops again to $\delta H_{\mathrm{obs}}$ and starts to regrow. We, however, expect that measurements also constrain the ice thickness upglacier. Therefore, we assume that the uncertainty can also decrease at a certain rate along the flow. This generic decrease rate is not known, but we assume the same magnitude as for the above error increase rate in Eq. (9).

$\nabla \cdot\left[(\boldsymbol{r}) \delta F_{2}\right]=(-1.0) \cdot\|\delta \dot{a}-\nabla \cdot[F \delta \boldsymbol{r}]\|$
This equation requires appropriate upstream boundary conditions, such that the error reaches $\delta H_{\text {obs }}$ at the next observation downglacier. Yet this is impractical, and we instead restate the problem as an upstream error increase well constrained at the measurements.

$\nabla \cdot\left[(-\boldsymbol{r}) \delta F_{2}\right]=\|\delta \dot{a}-\nabla \cdot[F \delta \boldsymbol{r}]\|$

The two problems Eqs. (9) and (11) are structurally identical to Eq. (1) and thus numerically solved as described in Sect. 2.2. The two formal error estimates $\delta F_{1}, \delta F_{2}$ subsequently enter a linear error propagation within the SIA fluxthickness relation (Eq. 7). This yields

$$
\begin{gathered}
\delta H_{i}=\frac{1}{n+2}\left[-\frac{2}{n+2} B^{-1 / n}(\rho g)^{n}\|\nabla h\|^{n}\right]^{-1 /(n+2)} \\
\cdot\|F\|^{-(n+1) /(n+2)} \cdot\left\|\delta F_{i}\right\| ; \quad i \in\{1,2\} .
\end{gathered}
$$

In this way, the error analysis is limited by the assumptions inherited from the SIA. Uncertainties in $B, \rho, g$ and $\nabla h$ are not accounted for. The final thickness error estimate $\delta H$ is the minimum of $\delta H_{1}$ and $\delta H_{2}$.

Input uncertainties for the test geometries are presented in Sect. 3.9. These uncertainties are chosen constant, which is problematic in terms of the iterative optimisation. The control variable $\dot{a}$ is gradually adjusted, and uncertainties of other input fields and underlying assumptions of the reconstruction approach are thus placed into this field. Yet it is not evident how to iteratively update the uncertainty associated with the control parameter and we accept some limitations here. The relevance of this assumption can be assessed from a comparison of the initial and the final AMB field (Appendix B).

Another source of uncertainty relies on the fact that the mass-conservation equation (Eq. 1) is valid only at an instant in time. Most input fields are, however, measured or derived over finite time intervals that naturally differ. Brinkerhoff et al. (2016) suggest that this additional uncertainty term could directly be added to the measurement error. Yet the magnitude is unclear for the individual fields and we therefore ignore it here.

\subsection{Second step: velocity-based solution}

In a second step, the thickness map is updated in areas where reliable surface velocity information is available by solving Eq. (1) directly for the glacier thickness. Equation (1) is vertically integrated and the surface velocity information needs to be first converted into a vertical mean value. Within the scope of this methodological study, we apply this second step exclusively where velocity magnitudes exceed $100 \mathrm{~m} \mathrm{yr}^{-1}$ (details of the sub-domain delineation in Sect. 2.4). In these subdomains, basal sliding is assumed to dominate over internal deformation, and therefore vertical mean and surface velocities are set equal. We rely on the same Elmer/Ice routine to discretise and solve the mass-conservation problem as above 
(Sect. 2.2). Previously inferred first-step thickness values are prescribed as Dirichlet conditions around the lateral domain margin, whereas no condition is imposed along marine ice front.

\subsubsection{Cost function and multi-parameter optimisation}

The ice-thickness solution is optimised as we cannot anticipate that input fields are consistent in terms of the mass balance equation. Yet in this step the optimisation makes use of three control variables. The AMB is complemented by both horizontal velocity components $u_{i}$. For this second-step optimisation, a new and more elaborate cost function $N$ is defined.

$$
\begin{aligned}
N= & \gamma_{\mathrm{pos}} \cdot \int_{\Omega} H^{2} \cdot H[-H] d \Omega \\
& +\gamma_{\mathrm{obs}} \cdot \int_{\Omega}\left(H-H_{\mathrm{obs}}\right)^{2} d \Omega \\
& +\gamma_{\text {marine }} \cdot \int_{\Gamma_{\text {marine }}} H^{2} \cdot H\left[H_{\min }-H\right] \cdot H\left[H-H_{\max }\right] d \Gamma \\
& +\gamma_{\mathrm{reg}} \cdot \int_{\Omega}\left(\frac{\partial H}{\partial x}\right)^{2}+\left(\frac{\partial H}{\partial y}\right)^{2} d \Omega \\
& +\gamma_{\dot{a}} \cdot \int_{\Omega}\left(\dot{a}-\dot{a}^{\text {init }}\right)^{2} d \Omega+\gamma_{U} \cdot \sum_{i=1}^{2} \int_{\Omega}\left(u_{i}-u_{i}^{\text {init }}\right)^{2} d \Omega
\end{aligned}
$$

Most of the terms have equivalents in Eq. (6). As before, we penalise a negative solution, high variability of the control variables and the control-variable mismatch to initial values. New terms are the penalty for thickness values that differ from the measurements $H_{\text {obs }}$ and the line integral along the marine boundary $\Gamma_{\text {marine. }}$ The latter integral penalises thickness values outside a certain range. The lower limit of this range stems from the fact that marine-terminating glacier margins on Svalbard are mostly grounded (Dowdeswell, 1989). Therefore, $H_{\min }$ is given by the flotation criterion $H_{\text {min }}=h \cdot \rho_{\text {water }} /\left(\rho_{\text {water }}-\rho_{\text {ice }}\right)$. The upper limit is calculated from the International Bathymetric Chart of the Arctic Ocean (IBCAO) bathymetry. We assume that the bed topography does not significantly decrease inland and thus that the bathymetry along the ice front should be shallower than the maximum depth at all ocean points within a $5 \mathrm{~km}$ radius. The multiplier choices are motivated as follows: first, the most decisive multiplier is $\gamma_{\text {reg. }}$. If chosen too high, boundary thickness values and measurements are simply smoothed without much consideration for the ice dynamic influence. If chosen too low, the thickness solution of adjacent flow lines decouples. The choice $\gamma_{\text {reg }}=10^{-2}$ represents a tradeoff between the two extremes. Second, we deemed it appropriate to set $\gamma_{\text {pos }}=\gamma_{\text {marine }}=\gamma_{\text {obs }}$. The value was gradually increased until the solution was appropriately affected, giving $\gamma_{\text {pos }}=10^{2}$. As before, the remaining two multipliers $\gamma_{\dot{a}}=10^{-4}$ and $\gamma_{U}=10^{-8}$ are not very decisive and they were mostly added to prevent divergent behaviour.

As above (Sect. 2.2.3), cost derivatives with respect to the control variables $\dot{a}$ and $u_{i}$ were computed from the adjoint system to Eq. (2). Without further modifications, the iterative optimisation preferentially modifies $\dot{a}$ because the control variables have different magnitudes. To align relative change values, a scaling factor of 0.05 for the velocity derivatives was introduced. Convergence of this second-step optimisation is reached using the same threshold criterion as above (Sect. 2.2.3).

\subsubsection{Error estimate}

Errors are again estimated following the ideas presented in Morlighem et al. (2014). As the ice thickness is calculated directly from mass conservation, errors only have to be propagated through Eq. (1). By analogy with Sect. 2.2.5, two systems of equations limit the error estimate.

$\nabla \cdot\left[(+\boldsymbol{u}) \delta H_{1}\right]=\|\delta \dot{a}-\nabla \cdot[F \delta \boldsymbol{u}]\|$
$\nabla \cdot\left[(-\boldsymbol{u}) \delta H_{2}\right]=\|\delta \dot{a}-\nabla \cdot[F \delta \boldsymbol{u}]\|$

The minimum value of the absolute values of these two error estimates gives the actual thickness error $\delta H=\min \left(\left\|\delta H_{1}\right\|\right.$, $\left.\left\|\delta H_{2}\right\|\right)$. Input uncertainty values are specified in Sect. 3.9. Other source terms of uncertainty are implicitly neglected (Sect. 2.2.5). These stem for instance from the iterative update of the control variable and the non-contemporaneous input fields.

\subsection{Gridding and boundary conditions}

Individual glacier outlines are first partitioned into marine and land-terminating segments by searching whether the surface elevation is 0 within $150 \mathrm{~m}$ of the outline point. Where the DEM showed more advanced glacier fronts than the glacier inventory, a marine termination is inferred within the same search radius but with $100 \mathrm{~m}$ as surface elevation threshold. Subsequently, nunataks are automatically accounted for in the mesh, if resolved by the target grid spacing. In addition, we added grid points at each location where thickness measurements were available. This was necessary to prescribe internal boundary conditions on the error estimates. High-resolution thickness measurements were subsampled a priori in accordance with the grid resolution. From the outline and measurement locations, a 2-D mesh with triangular elements was generated using the open-source finiteelement grid generator Gmsh (http://gmsh.info/ (Geuzaine and Remacle, 2009). Nodal values for all input fields are determined relying on a standard natural-neighbour Sibsonian interpolation procedure (Fan et al., 2005).

In the first-step reconstruction, two external boundary conditions are necessary around the glacier domain. At outflow boundaries along marine ice fronts, no condition is imposed 
on the ice flux. Where glaciers terminate on land, a zeroflux Dirichlet condition is imposed. For the error estimation, internal boundary conditions are applied at thickness measurement locations. There, $\delta F_{1}, \delta F_{2}$ are set in accordance to reported thickness measurement errors (Sect. 3.9). In the second step, the domain is reduced to sub-domains with reliable velocity information. In each drainage basin, the largest sub-domain is chosen from all areas in which velocity observations exceed $100 \mathrm{~m} \mathrm{yr}^{-1}$. At the lateral boundaries of this sub-domain, ice-thickness values as well as thickness error estimates are prescribed from the first-step reconstruction. No boundary conditions are imposed along marine ice fronts. At thickness measurement locations, Dirichlet conditions are imposed on the up- and downstream error propagation. Dirichlet conditions are set to the larger of two values, being either the reported measurement error or the actual mismatch $\left(H-H_{\mathrm{obs}}\right)$. The latter changes iteratively.

\section{Test geometries}

The two-step reconstruction approach is tested on three ice geometries on Svalbard, where an abundant record of thickness observations was available (Fig. 1). The three test geometries are Vestfonna ice cap on Nordaustlandet, the landterminating Werenskioldbreen, and the glacier complex composed of the marine-terminating Austre Torellbreen, Hansbreen and Paierlbreen (THPB). The latter two geometries are located in Wedel Jarlsberg Land. Input requirements are the glacier outline, the surface geometry, the surface mass balance, surface elevation changes and surface velocities. Fjord bathymetry information and thickness measurements are used to constrain the inferred thickness values.

\subsection{General characteristics}

VIC is the second largest ice cap on the Svalbard archipelago (Fig. 1; Dowdeswell, 1986a). According to the 2002-2010 glacier inventory, it covers an area of $2366 \mathrm{~km}^{2}$ with its summit area lying at $630 \mathrm{~m}$ a.s.l. (above sea level). Ice flow is channelled through several elongate outlet glaciers, which drain radially from a central crest and export ice to the surrounding ocean (Fig. $2 \mathrm{~g}$ ). Despite the steady retreat of most outlet glaciers since the 1970s (Dowdeswell, 1986b; Braun et al., 2011), Søre and especially Nordre Franklinbreen advanced notably. This readvance coincided with a strong acceleration reaching far inland. Surface velocities doubled and now exceed $100 \mathrm{~m} \mathrm{yr}^{-1}$ over a large area (Pohjola et al., 2011). Prior to the speed-up, most of the ice was exported via the northern branch of Nordre Franklinbreen. In the meantime, ice velocities indicate that the southern branch is the more prolific export path (Fig. 2g). The bimodal pattern in ice dynamics is overprinted by cyclic surges with the last active phase reported in 1952 for Søre Franklinbreen (Błaszczyk et al., 2009). Surges are quasiperiodic cycles of

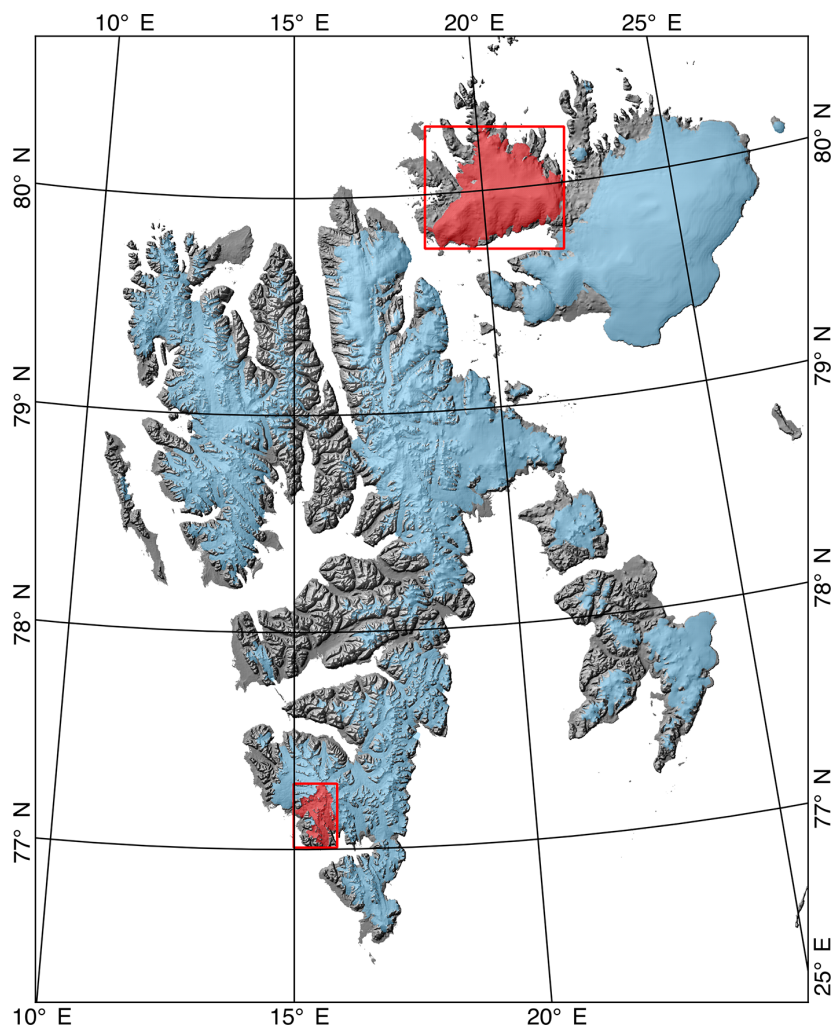

Figure 1. Overview map of the Svalbard archipelago showing ice coverage (blue shading). The three test sites are located in two areas on the archipelago (red shading and rectangles). The test sites are Vestfonna ice cap (VIC) on Nordaustlandet, the glacier complex comprising the marine-terminating Austre Torellbreen, Hansbreen and Paierlbreen (THPB), and the land-terminating Werenskioldbreen (WSB) in Wedel Jarlsberg Land. Background: grey-scale hillshaded topography based on a $50 \mathrm{~m}$ DEM from the Norwegian Polar Institute (NPI; http://publicdatasets.data.npolar.no/kartdata/NP S0_DTM50.zip).

an active phase, during which extremely fast flow can transfer an immense ice volume downglacier, followed by a quiescent phase during which the ice cover in the accumulation area gradually regains its former height. Two other surgetype glaciers are known in the eastern part of Vestfonna. Active phases were reported in 1939 and 1992 for Rijpbreen and during the period 1973-1980 for Bodleybreen (Dowdeswell, 1986b; Błaszczyk et al., 2009).

Austre Torellbreen is a marine-terminating glacier (Fig. 2b) that calves into Skoddebukta and spans altitudes from sea level to about $900 \mathrm{~m}$ a.s.l. The most elevated parts of the accumulation area belong to Amundsenisen (above $700 \mathrm{~m}$ a.s.l.). This area is drained by Bøygisen and Løveisen. Before reaching the ocean, Austre Torellbreen is fed by Vrangpeisbreen from the south. Across the divide in the south lies Hansbreen, which has a dominant main branch receiving important lateral inflow from two prominent tributaries in the southwest, i.e. Deileggbreen and Tuvbreen 

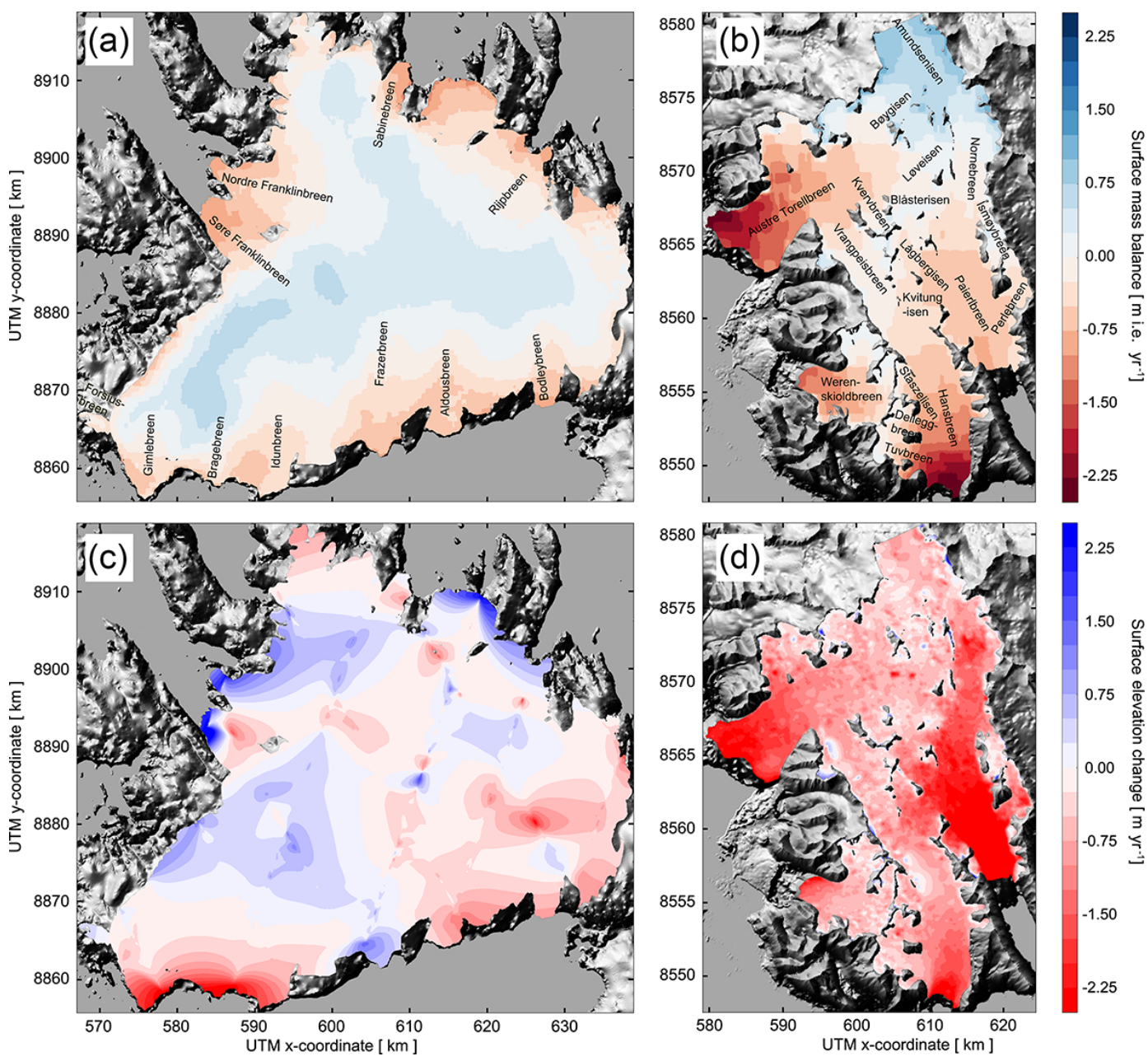

Figure 2.

(Grabiec et al., 2012). The glacier shows a somewhat reduced elevation range, only up to $500 \mathrm{~m}$ a.s.l. Beyond the mountain range to the east lies Paierlbreen. Both glaciers are well connected via Kvitungisen. Paierlbreen connects again back to Amundsenisen in the north via Nornebreen. The glacier was not only classified as marine terminating in the 2002-2010 inventory, but it also exhibited surge behaviour in 1993-1999 (Błaszczyk et al., 2009; Nuth et al., 2013). During the surge, the ice-front position was not affected much. The reason might be that the surge event was superimposed on the well-documented retreat of all marineterminating glaciers in the Hornsund area over the last century (Błaszczyk et al., 2013). Austre Torellbreen, Hansbreen and Paierlbreen cover areas of 141, 64 and $99 \mathrm{~km}^{2}$, respectively. West of the THPB complex lies Werenskioldbreen (Ignatiuk et al., 2014). WSB is land terminating and somewhat smaller with $27 \mathrm{~km}^{2}$.

\subsection{Glacier outlines}

Glacier outline information is taken from the 20022010 glacier inventory described in Nuth et al. (2013). As THPB is a well-connected glacier complex, adjacent glacier boundaries were removed and joined into one single outline. WSB was not merged with the THPB complex because the shared ice divide is short and shallow (Kosibapasset has only $\sim 15 \mathrm{~m}$ depth). VIC is treated as a single entity by merging all its individual drainage basins. In this way, we avoid discontinuities in the anticipated thickness solution across ice ridges and divides.

\subsection{Surface elevation}

Concerning the Svalbard surface elevation, we rely on a $50 \mathrm{~m}$ digital elevation model from the 1990s (Norwegian Polar Institute, 2014) provided by the Norwegian Polar Institute (NPI). This map was produced from areal photos using photogrammetry as well as from contour lines in earlier elevation maps, which were digitised and interpolated. We re- 

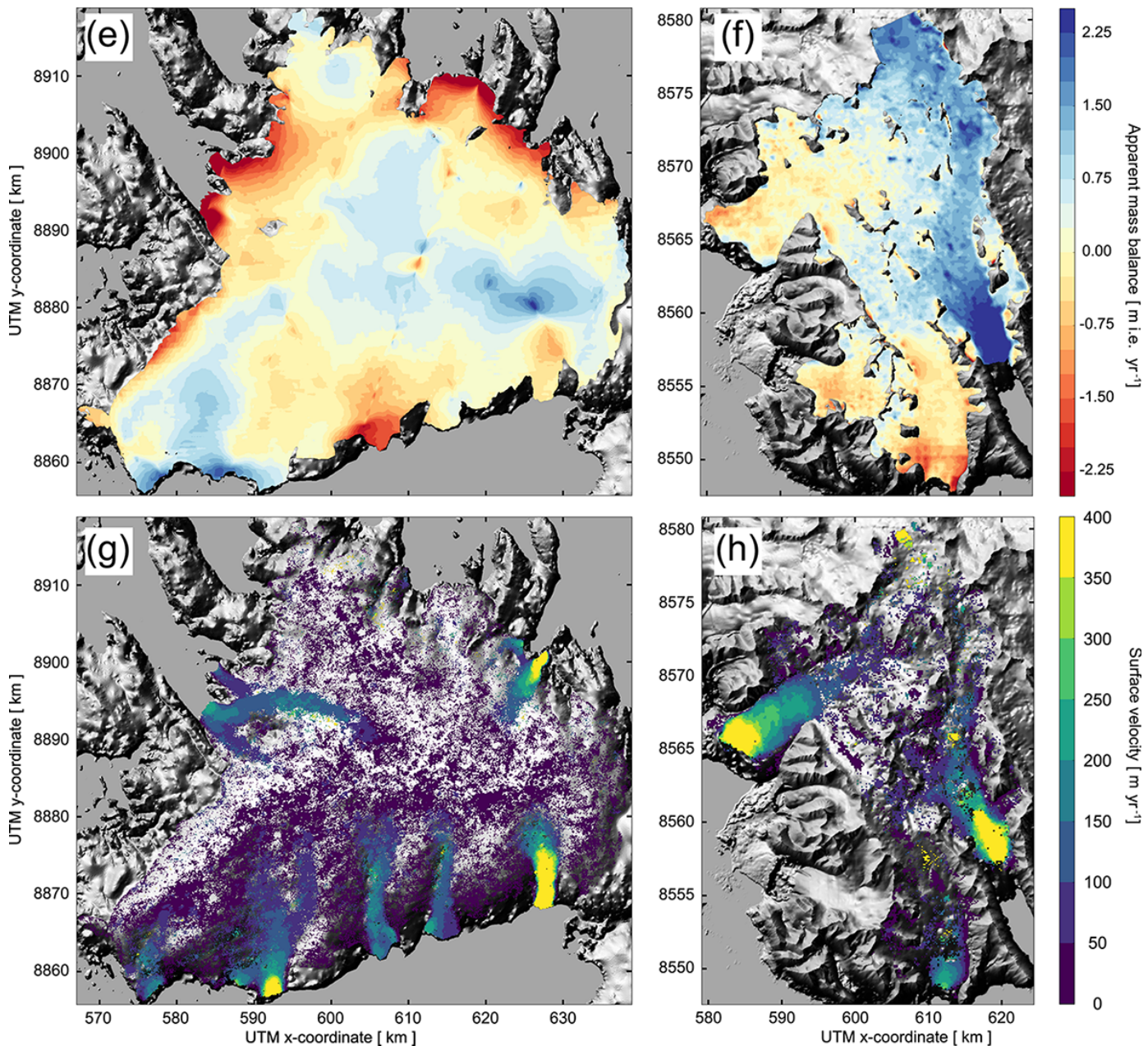

Figure 2. Input fields to the ice-thickness reconstruction for VIC (a, c, e, g), THPB and WSB (b, d, f, h). Surface mass balance (SMB) input (a, b) is provided by MAR as an average over the period 1979-2014 (Lang et al., 2015). Elevation changes on VIC (c) are inferred from 2003-2007 ICESat profiles. The line information along the ICESat track was linearly interpolated. In southern Spitsbergen, elevation changes (d) were inferred from DEM differencing. A 2008 SPOT-HRS DEM was referenced to the 1990 DEM from the Norwegian Polar Institute (NPI, http://publicdatasets.data.npolar.no/kartdata/NP_S0_DTM20.zip). The difference between SMB and surface elevation changes (e, f) is referred to as the AMB. Surface velocity magnitudes $(\mathbf{g}, \mathbf{h})$ were inferred from 2015-2016 Sentinel-1 imagery. Background: grey-scale hill-shaded topography based on a NPI 50 m DEM (http://publicdatasets.data.npolar.no/kartdata/NP_S0_DTM50.zip).

frained from using this DEM for VIC where it is based on contour-line information resulting in a characteristic wave pattern in the slope field. Therefore, we use a more recent $10 \mathrm{~m}$ DEM inferred from 2010 radar data acquired by the TanDEM-X mission, operated by the German Aerospace Center (DLR; Krieger et al., 2013). The DEM was processed from bi-static synthetic aperture radar (SAR) data using a differential interferometric approach (Seehaus et al., 2015; Rankl and Braun, 2016; Vijay and Braun, 2016). It was referenced to sea level by laser altimetry measurements with the Ice, Clouds, and Land Elevation Satellite (ICESat) (Schutz et al., 2005).

\subsection{Thickness measurements}

VIC thickness measurements (Fig. 4a) were obtained from $60 \mathrm{MHz}$ airborne radio-echo sounding (RES) surveys between 1983 and 1986 (Dowdeswell et al., 1986). Five flight lines run north-south across the ice cap and two from east to west. All profiles follow centrelines of prominent outlet glaciers. Unfortunately, no bed reflector could be identified for a large portion of these airborne data, including most of the ice-divide area. Recently in 2008-2009, groundpenetrating radar (GPR) data were collected by Pettersson et al. (2011). Following Pettersson et al. (2011), the early airborne measurements were adjusted assuming a constant thinning rate of $\sim 0.16 \mathrm{~m} \mathrm{yr}^{-1}$ over the entire ice cap. In addition, they estimate the measurement error for the early air- 
borne surveys from Dowdeswell et al. (1986) to be $23.1 \mathrm{~m}$, whereas the more recent GPR data shows a 9.3 m uncertainty.

In the Hornsund area, Hansbreen is well studied and an ice-core drilling team reached the bed at three locations in 1994 (Jania et al., 1996). Between 2004 and 2013, GPR profiles were collected both on THPB and WSB (Navarro et al., 2014). These surveys provide a dense grid over most parts of these glaciers (Fig. 4b). Therefore, the early icecore information was discarded here because it only gives information at three additional points and because it is not evident how to reliably estimate surface elevation changes since the early 1990s. For WSB, the GPR measurement error was analysed in depth accounting for positioning-related icethickness uncertainty (Lapazaran et al., 2016). Measurement errors fall into a range of 3.3 to $6.8 \mathrm{~m}$ with an average value of $4.5 \mathrm{~m}$. These error values ignore a known uncertainty term originating from 2-D data migration (Moran et al., 2000). This migration is common practice, but it ignores transversal bedrock slopes. This processing uncertainty attains up to $14 \mathrm{~m}$ for a certain part of a small and shallow Alaskan valley glacier. It is impossible to determine a priori this uncertainty for each measurement on Svalbard, and we therefore ignore this source term here.

\subsection{Surface mass balance}

For the SMB information, we rely on the regional climate model MAR (Modèle Atmopshérique Régional; Lang et al., 2015). MAR combines a hydrostatic model for the atmospheric circulation with a physically based model for snowpack evolution. The MAR-SMB simulations cover the entire archipelago (Fig. 2a and b) and were validated by Lang et al. (2015) against available climatic variables as well as SMB measurements from Pinglot et al. (1999, 2001). The difference between modelled SMB values and 10 used validation sites shows a low bias of $-0.03 \mathrm{mi}$ i.e. $\mathrm{yr}^{-1}$ with a standard deviation of 0.14 mi.e. $\mathrm{yr}^{-1}$. The latter value is considered as an uncertainty estimate for the SMB field. Simulations were conducted on a regular $7.5 \mathrm{~km}$ grid, but a downscaled output was provided on $200 \mathrm{~m}$ spacing using an interpolation strategy that distinguishes the various SMB components (Franco et al., 2012). The components are interpolated according to locally defined, vertical gradients. For the reconstruction, the annual SMB record was averaged over 1979-2015.

To assess the sensitivity of the thickness reconstruction to the SMB input (Appendix C1), results from the Weather Research and Forecasting Model (WRF) were considered (Aas et al., 2016). The WRF-SMB field represents the period 2003-2013 and has a $3 \mathrm{~km}$ resolution. The field could not be downscaled as above for the MAR results. Therefore, the SMB sensitivity is only assessed on the larger VIC geometry.

\subsection{Surface elevation changes}

Over VIC, 2003-2007 elevation changes (Fig. 2c) were inferred from ICESat altimetry measurements (Moholdt et al., 2010). The laser altimetry system has a footprint of $70 \mathrm{~m} \mathrm{di-}$ ameter with $170 \mathrm{~m}$ along-track spacing. Across-track spacing is irregular and much larger with several kilometres. A natural-neighbour Sibsonian interpolation ${ }^{1}$ (Fan et al., 2005) is used to estimate elevation changes in between these scattered ICESat measurements. Moholdt et al. (2010) report that the local root-mean-square deviation of several hundred surface-change estimates is $0.3 \mathrm{~m} \mathrm{yr}^{-1}$.

For Wedel Jarlsberg Land, elevation changes were calculated by differencing the NPI $20 \mathrm{~m}$ DEM (Norwegian Polar Institute, 2014) from 1990 with a 40 m DEM inferred from 2008 imagery acquired by the high-resolution stereoscopic (HRS) sensor on-board SPOT 5 (Korona et al., 2009). The DEMs were first co-registered (Nuth and Kääb, 2011) before subsequent differencing and resampling to $100 \mathrm{~m}$ (Fig. 2d). No information on the DEM differencing uncertainty was available.

\subsection{Surface velocities}

Using satellite imagery acquired between January 2015 and September 2016 by the C-band synthetic aperture radar onboard Sentinel-1, we apply intensity offset tracking to consecutive image pairs (Strozzi et al., 2002; Seehaus et al., 2016). The time series of displacement fields is first filtered for obvious outliers within a kernel size scaling with the prevailing flow direction and magnitude (Seehaus et al., 2016). Then, fields are stacked using median averaging to obtain maximum coverage and to reduce effects from short-term or seasonal fluctuations (Fig. 2g and h). Velocity maps are provided at $100 \mathrm{~m}$ resolution. The uncertainty associated to the inferred velocity maps is estimated on 70 stable reference areas without ice cover. We find an average uncertainty of $19 \mathrm{~m} \mathrm{yr}^{-1}$, which is comparable to independent uncertainty estimates for merged Sentinel-1 imagery with minimum values of $\sim 17 \mathrm{~m} \mathrm{yr}^{-1}$ (Schwaizer, 2016).

\subsection{Fjord bathymetries}

Information on the fjord bathymetry is used to further constrain the thickness reconstruction at marine ice fronts. The new International Bathymetric Chart of the Arctic Ocean (IBCAO version 3.0; http://www.ibcao.org/) holds a wealth of new measurements around the Svalbard archipelago (Jakobsson et al., 2012). It comprises several recent multibeam surveys that entered deep into some major fjords and collected high-resolution seafloor information (Ottesen et al., 2007). Around the archipelago, the new IBCAO map is provided at a spatial resolution of $500 \mathrm{~m}$.

\footnotetext{
${ }^{1}$ Source code available at: https://github.com/sakov/nn-c/tree/ master/nn.
} 

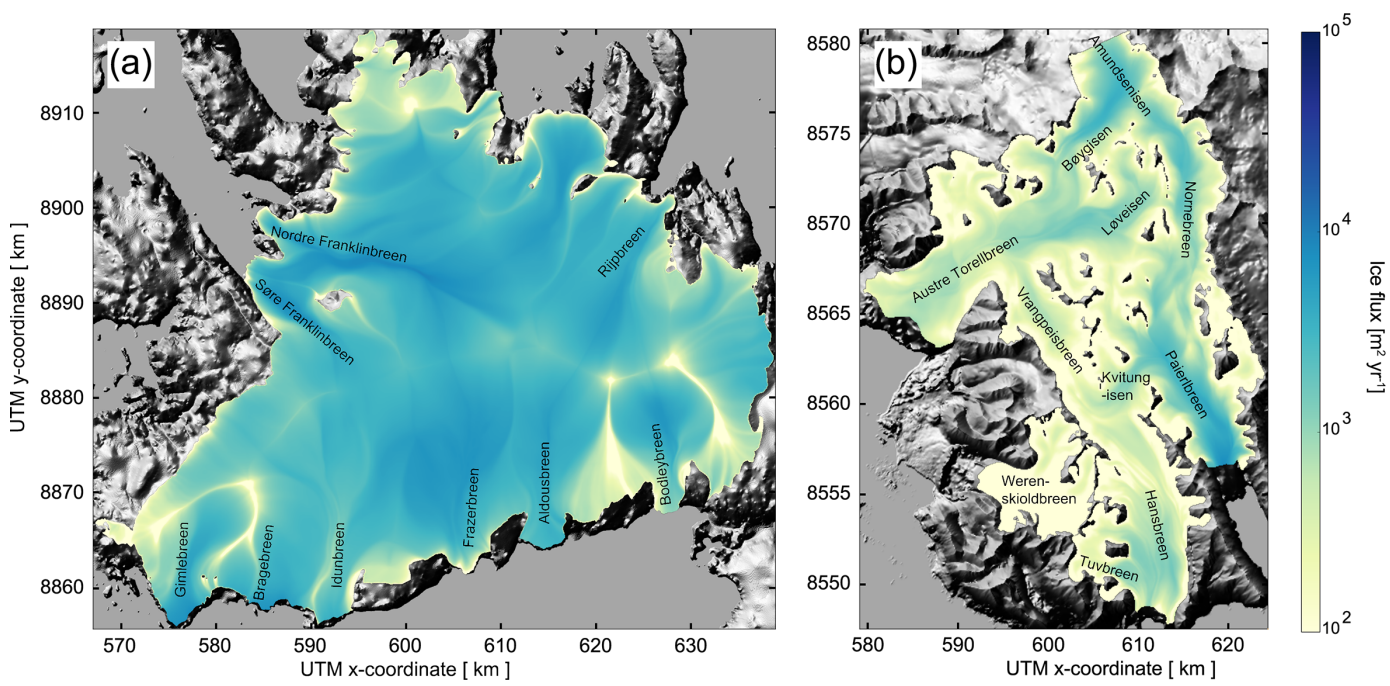

Figure 3. Ice-flux solution after cost optimisation for VIC (a), THPB and WSB (b). Starting at the ice crest on VIC, ice flux gradually increases and converges. Before the ocean is reached, the outflow is channelled through several major outlet glaciers. Flux values at marine ice fronts are a natural result of the mass overturning. Background: grey-scale hill-shaded topography based on a NPI $50 \mathrm{~m}$ DEM (http: //publicdatasets.data.npolar.no/kartdata/NP_S0_DTM50.zip).

\subsection{Grid specifications and input uncertainties}

The target resolution for the meshing is set to $200 \mathrm{~m}$ for THPB and VIC and $100 \mathrm{~m}$ for WSB. Observations for all test geometries are very densely spaced and we decided to only keep measurements that are more than $50 \mathrm{~m}$ apart, which is half of the minimum grid spacing. The initial 20792, 44921 and 21273 measurements collected on VIC, THPB and WSB were thus reduced to 4475,5945 and 1189 points, respectively.

From the above presentation of the input fields available for the test geometries, we define input uncertainties for the formal error propagation in Sects. 2.2.5 and 2.3.2. First, the Dirichlet conditions on the error on the WSB and THPB thickness measurement $\delta H$ is set to $5 \mathrm{~m}$ (Lapazaran et al., 2016). For VIC, we prescribe 10 and $25 \mathrm{~m}$ for the ground and airborne RES data, respectively (Pettersson et al., 2011). Second, the AMB uncertainty is estimated to be $\delta \dot{a}=0.4 \mathrm{~m} \mathrm{yr}^{-1}$, which is the sum of the individual error estimate reported for SMB and surface elevation changes (Sects. 3.5 and 3.6). For the first-step reconstruction, we estimate a $20 \%$ error in the flux direction $\delta r$. Only a scalar estimate is necessary here because of the normalisation of the direction vector $\boldsymbol{r}$. The surface velocity uncertainty is directly inferred from ground control points: $\delta u=20 \mathrm{~m} \mathrm{yr}^{-1}$.

\section{Results and discussion}

\subsection{First-step reconstruction}

This section covers the presentation and discussion of the iceflux solution, the reconstructed thickness and bedrock eleva- tion fields as well as the error estimates. In the error analysis, actual mismatch values from a fraction of withheld measurements are compared to the formal error estimate (Sect. 2.2.5). In the appendix, interested readers find a brief discussion of the viscosity parameter (Appendix A) and a sensitivity assessment with respect to changes in SMB and in the surface geometry as well as with respect to a flux correction (Appendix C).

\subsubsection{Ice flux}

For Vestfonna ice cap, the ice-flux field is very instructive (Fig. 3). For many drainage basins, ice flux is small near the ice divide and gradually increases downglacier. The increase results from ice accumulated along flow lines as well as from flow convergence towards the lateral margin. Often, ice flux is highest near the equilibrium line altitude. For Gimlebreen, Bragebreen, Idunbreen, Aldousbreen and Bodleybreen, ice flux remains elevated up to the marine ice fronts. For Gimlebreen, Bragebreen and Idunbreen, these high values are explained by an increasingly positive $\dot{a}$ towards the ice front (Fig. 2e). Also for Aldousbreen, $\dot{a}$ stays positive near the glacier tongue. Unlike these examples, the AMB turns negative long before the margin is reached for Nordre Franklinbreen and Frazerbreen. There, elevated iceflux values are maintained by strong convergence. For Nordre Franklinbreen, the ice flux mainly follows the southern branch.

For WSB and THPB, the ice flux is small all along the land-terminating margin and increases towards centrelines. For Austre Torellbreen, we find strong flux convergence along Bøygisen and Løveisen. Further downstream, ice-flux 

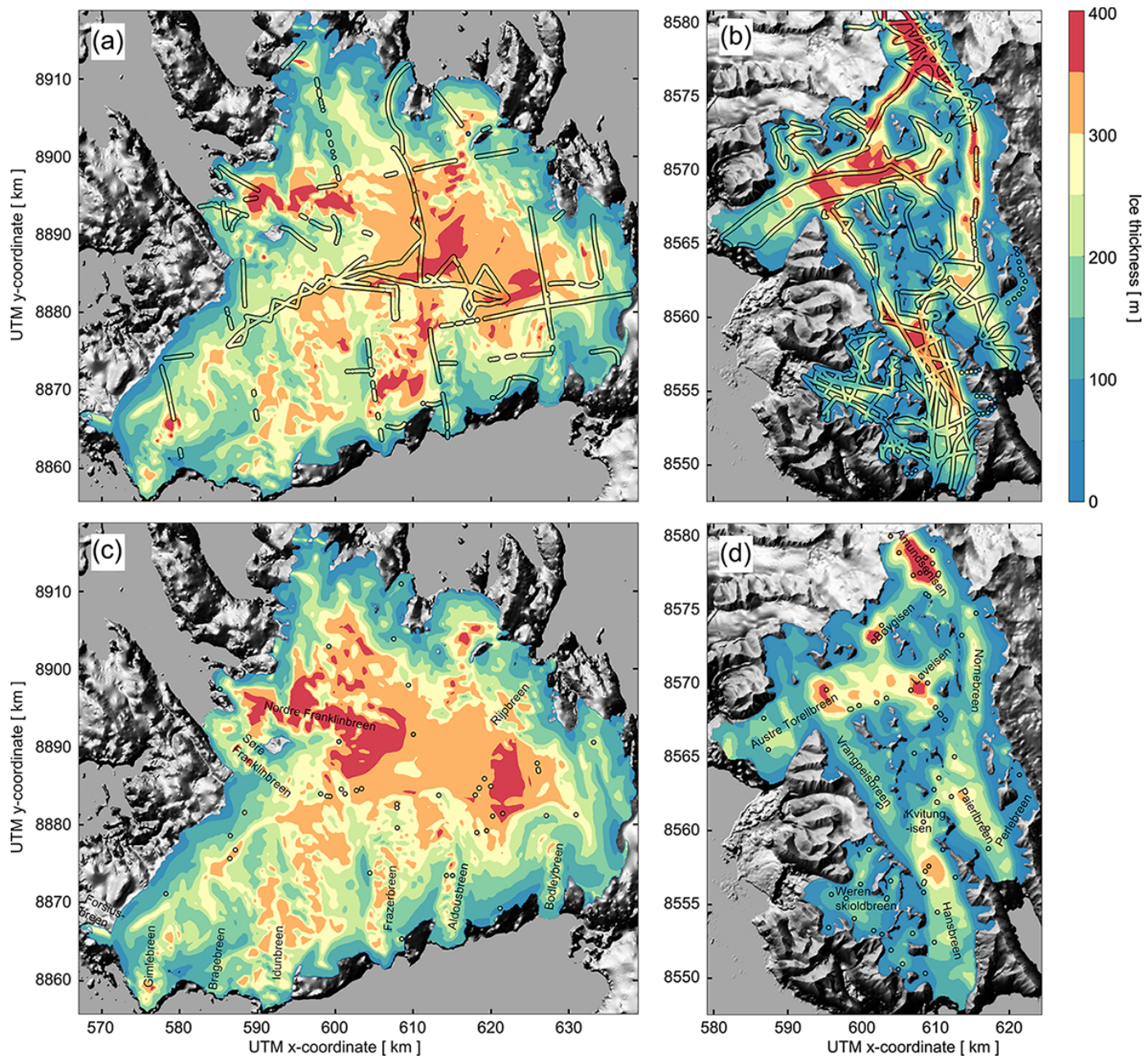

Figure 4. First-step ice-thickness map for VIC (a, c), THPB and WSB (b, d) accounting for thickness measurements. Thickness values for marine ice fronts are non-zero and a natural outcome of the underlying mass budget calculation. For VIC, thickness measurements (coloured dots) were collected with airborne radio-echo sounding instruments (Dowdeswell et al., 1986) as well as with ground-based pulsed radar systems (Pettersson et al., 2011; Navarro et al., 2014). For THPB and WSB, measurements were collected during several GPR campaigns between 2004 and 2012 (Navarro et al., 2014). The upper (a, b) and lower (c, d) panels show the respective thickness fields when all or only $1 \%$ of all thickness measurements were used in the first-step reconstruction, respectively. For the ice cap, mean thickness values are not very sensitive to the data availability, whereas the not well constrained reconstruction for THPB and WSB produces low biased estimates. Background: grey-scale hill-shaded topography based on a NPI 50 m DEM (http://publicdatasets.data.npolar.no/kartdata/NP_S0_DTM50. zip).

magnitudes remain constant as the AMB is close to zero. Unlike this balanced situation, a pronounced surface subsidence over most of Paierlbreen is not explained by the SMB and results in a positive AMB over the entire catchment area. This imbalance is compensated by extensive downwasting implying a gradual flux increase up to the marine ice front. The imbalance itself might partially reflect the long-term geometric adjustment of Paierlbreen to the surge in 1993-1999. Yet we cannot exclude that the SMB model underestimates the magnitude of surface melting or that a bias is introduced by the DEM differencing (Sect. 3.6). In any case, the Paierlbreen setup is challenging because there is almost no sink in the $\mathrm{AMB}$ and ice is primarily lost via the marine ice front. The main branch of WSB shows very small flux values. The reason is that source areas $(\dot{a}>0$ in Fig. $2 \mathrm{f})$ are very limited and located on two small glacier branches joining from the north. Though they provide a certain ice flux, values along the main branch remain close to zero. Under the input SMB and elevation-change fields, no important ice-dynamic balancing is required.

\subsubsection{Ice thickness and bedrock elevation}

The first-step thickness map (Fig. 4) depends on surface slopes, thickness measurements and the ice-flux solution. The latter reflects both climatological and geometric infor- 

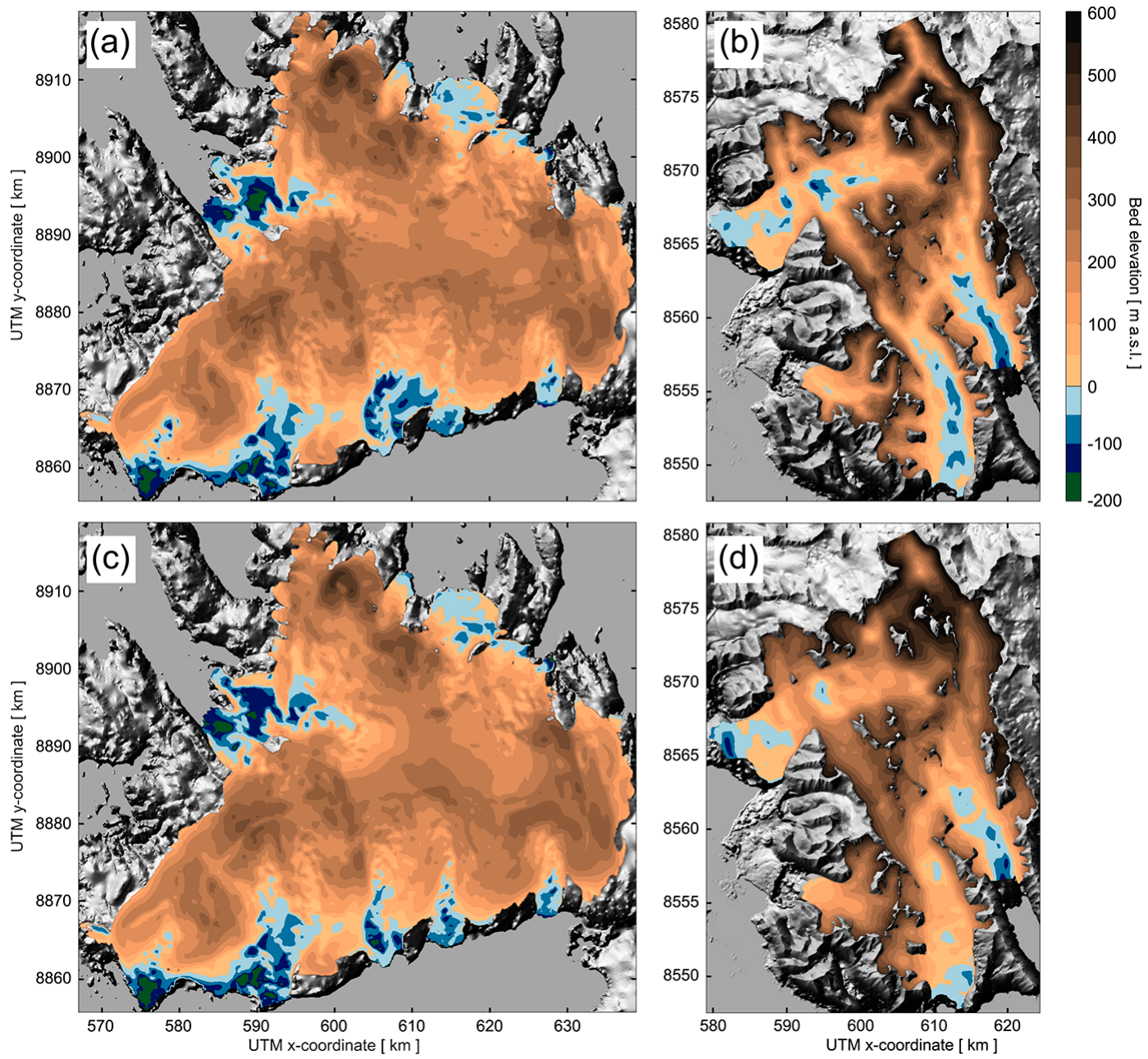

Figure 5. Bedrock topography associated to the thickness field in Fig. 4 for VIC (a, c), THPB and WSB (b, d). In absence of direct measurements, negative values over larger areas were not anticipated for Gimlebreen and Idunbreen based on a direct interpolation of thickness data (Pettersson et al., 2011). Upper and lower panels reflect the respective amount of considered thickness measurements as in Fig. 4. Ice-free background: grey-scale hill-shaded topography based on a NPI $50 \mathrm{~m} \mathrm{DEM} \mathrm{(http://publicdatasets.data.npolar.no/kartdata/NP}$ S0_DTM50.zip). Ice-covered background: grey-scale hill-shaded bedrock topography.

mation. For VIC, we find a mean thickness of $228 \mathrm{~m}$ (Table $\mathrm{C} 1$ ). This value is significantly higher than the previously reported $185 \mathrm{~m}$, which was inferred from a direct kriging interpolation (Pettersson et al., 2011) of the same observations that entered our reconstruction. One reason for the differences is that our reconstruction produces thicker ice along outlet glacier troughs. Such deep and often overdeepened channels (Frazerbreen and Franklinbreen in Fig. 5) are explained by convergent ice flow draining large zones of the ice-cap accumulation area (Dowdeswell and Collin, 1990). For Bragebreen and Gimlebreen, the reconstruction suggests deep troughs which arise from a very positive AMB. The troughs are absent in the kriging interpolation as no observations were collected in these regions. Another reason for the differences is that kriging is expected to underestimate the ice thickness along the land-terminating margins away from observations. For our approach, the margin thickness is affected by physical quantities such as ice flux and surface geometry. An illustrative example for this effect is the dome-like surface topography of Forsiusbreen in the southwest of VIC. This glacier is almost disconnected from the main ice cap and the closest thickness measurements were taken more than $10 \mathrm{~km}$ away. As a consequence, Pettersson et al. (2011) generate limited thickness values from kriging. In our reconstruction, a small ice dome is predicted (Fig. 4a) that is even grounded slightly below sea level in its central areas (Fig. 5a). In general, the first-step thickness map suggests that more than $13.3 \%$ of the ice-covered area is grounded below sea level. Previously, it was thought that only a $5 \%$ area fraction lay below sea level, due to limited measurements from the outer part of the ice cap. In terms of total ice volume, 
the first-step thickness map yields $540.2 \mathrm{~km}^{3}$ as compared to the $442 \mathrm{~km}^{3}$ from kriging (Pettersson et al., 2011).

For the THPB and WSB systems in southern Spitsbergen (Fig. 4b), an abundant observational record was available. Therefore, we expect that relative differences between thickness maps from a direct interpolation and the first-step reconstruction should be small. From a direct kriging interpolation by Navarro et al. (2014), the mean thickness estimate for the THPB system is $184 \mathrm{~m}$ as compared to $176 \mathrm{~m}$ here (Table C1). For the land-terminating WSB, a mean thickness of 119 and $112 \mathrm{~m}$ is found. Relative differences between these values are smaller than $6 \%$. The slightly updated volume estimates are then 53.5 and $3.0 \mathrm{~km}^{3}$, respectively. Despite the similarity in these values, we see several systematic differences in the thickness maps from these two approaches. First, the kriging map shows that the measurements were interpolated, ignoring the presence of some ice-free nunataks (for example above the confluence of Bøygisen and Løveisen in Fig. 4 in Navarro et al., 2014). Similarly, ice thickness does not tend to zero along some land-terminating margins. These positive biases are compensated in other areas, where thickness measurements are not reproduced after kriging. A clear difference is seen along Vrangpeisbreen. In its upper reaches, the direct interpolation shows values below $100 \mathrm{~m}$ (Fig. 4 in Navarro et al., 2014), whereas the thickness measurements along the centreline readily exceed $200 \mathrm{~m}$ (Fig. 4b). These measurements are by construction reproduced here. Turning to the basal topography, we find elongate troughs reaching far upglacier from the marine terminus (Fig. 5b). The bedrock elevation is below zero over $12 \%$ of the entire THPB area. For Hansbreen, the bed remains below sea level almost up to Kvitungisen.

For many glaciers, only few or even no thickness measurements are available, and, therefore, we want to asses a lack of in situ measurements. For this purpose, we recomputed all thickness fields relying on a random $1 \%$ sample of all thickness measurements (Fig. 4c and d). For VIC, we find a slightly larger value for the mean ice thickness of $230 \mathrm{~m}$ and the total ice volume of $543.3 \mathrm{~km}^{3}$ (Table C1). General characteristics of the basal topography are already imprinted in the poorly informed reconstruction (Fig. 5c). For THPB and WSB, the mean ice-thickness values are reduced to 145 and $100 \mathrm{~m}$ from previously 176 and $112 \mathrm{~m}$, respectively. For THPB, the substantial thickness reduction implies that the area fraction grounded below sea level falls from 12 to $8 \%$. In many places, the sparsely informed reconstruction underestimates the depth of elongate, narrow bed troughs (e.g. Nornebreen, Vrangpeisbreen). The densely spaced GPR grid measured on Hansbreen provides an ideal test case to estimate how well the reconstruction performs without many measurements. Though an elongated bed trough is predicted, thickness values and the slope of lateral valley sides are underestimated. Moreover, the patterns in the bedrock topographies differ (Fig. 5b and d). These differences imply that not all features in the bedrock topography are necessarily well
Table 1. Fraction of all validation measurements for which the absolute mismatch is less than the predicted error estimate. Values are given in percent.

\begin{tabular}{lrcc}
\hline \multirow{2}{*}{ Fraction of withheld } & \multicolumn{3}{c}{ Test geometries } \\
\cline { 2 - 4 } measurements (\%) & VIC & THPB & WSB \\
\hline 99 & 84.0 & 63.9 & 88.7 \\
95 & 89.0 & 80.0 & 87.0 \\
90 & 93.0 & 79.4 & 91.1 \\
80 & 94.7 & 82.8 & 94.1 \\
70 & 96.2 & 86.0 & 93.4 \\
60 & 97.3 & 88.6 & 96.1 \\
50 & 97.3 & 88.7 & 95.6 \\
40 & 97.9 & 89.2 & 96.8 \\
30 & 97.9 & 89.5 & 96.9 \\
20 & 97.5 & 89.5 & 98.0 \\
10 & 98.4 & 91.2 & 96.6 \\
1 & 100.0 & 93.1 & 90.9 \\
\hline
\end{tabular}

imprinted in the glacier surface nor the flux field. Admittedly, a certain degree of details in the slope field is removed by the geometric smoothing (Sect. 2.2.1).

\subsubsection{Thickness error estimates}

The following error analysis is two-fold: we first present and discuss error-estimate maps from the formal error propagation of input uncertainties as described in Sect. 2.2.5. Secondly, we split the abundant thickness measurement record into two subsets. One subset is used in the reconstruction (Sect. 2.2.4), whereas the remainder is withheld for validation. The validation subset is used to infer actual mismatch values at the respective measurement location. Average values for the actual mismatch are then compared with the respective formal error estimates.

\section{Estimates from error propagation}

Relying on a formal error propagation (Sect. 2.2.5), it becomes possible to provide an error map (Fig. 6a and b). Using all thickness observations, the survey tracks are visible as small values in all error maps. Away from these measurements, error estimates gradually increase in both direction along streamlines. More abrupt variations are found perpendicular to the inferred flux direction. We therefore suggest that future measurement campaigns should give priority to across-flow profiles. Values are highest in areas where ice flux is small, as for example along the southwestern part of the VIC divide and on a large part of the land-terminating WSB. For the latter area, error estimates are largest. These extreme values are caused by negligible ice flux over a major part of the domain (Sect. 4.1.1). The error-estimate map of VIC also highlights that measurements should ideally be acquired on both sides of an ice divide. For Idunbreen, no mea- 

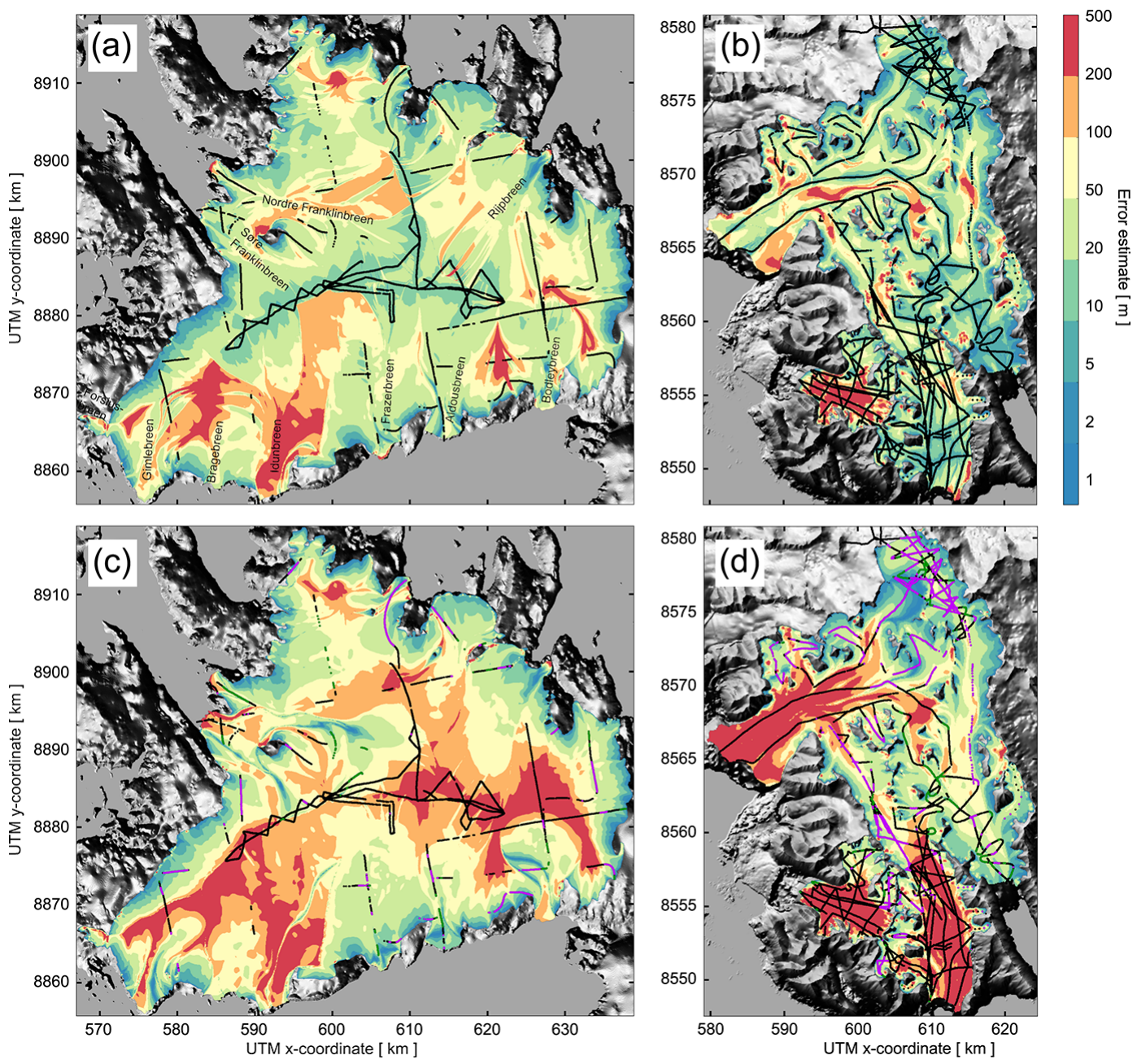

Figure 6. Error-estimate map based on the error propagation presented in Sect. (2.2.5) for VIC (a, c), THPB and WSB (b, d). Values are most elevated in the vicinity of unconstrained ice divides and ridges as well as in other stagnant areas. Error estimates are equal to the measurement uncertainty where observations were collected. Upper and lower panels reflect the amount of considered thickness measurements as in Fig. 4. Black dots indicate the measurement locations. For the withheld fraction of measurements, dots are coloured where the difference between observed and reconstructed thickness values exceeds the error bounds. For these outliers, green or purple colours indicate that observations are strongly over- or underestimated by the reconstruction, respectively. Background: grey-scale hill-shaded topography based on a NPI $50 \mathrm{~m}$ DEM (http://publicdatasets.data.npolar.no/kartdata/NP_S0_DTM50.zip).

surements were obtained (Fig. 4a), which leads to elevated error estimates over most of this drainage basin (Fig. 6a). Thickness measurements collected just across the ice divide were not transmitted over the crest to the Idunbreen catchment area.

Considering only $1 \%$ of all thickness measurements, the error estimates become larger (Fig. $6 c$ and d). The ice-cap setup (VIC) shows the largest values along ice divides and ridges where flux values are smallest (Fig. 6c). On WSB and THPB (Fig. 6d), maximum error estimates are again found in the stagnant areas on WSB, but values on Hansbreen and Austre Torellbreen are also elevated. In critical areas on ice caps and glaciers, we confirm that local error estimates can readily reach $50 \%$ of the inferred ice thickness if thickness measurements are sparse.

\section{Actual thickness mismatch}

A pressing question is whether the magnitude of these errorestimate maps is reliable and falls into a realistic range. For this purpose, we withheld a random sample of all thickness measurements from the reconstruction and computed an absolute thickness mismatch for comparison. The sample size is defined as a fraction of all measurements and we investigated the range from 1 to $99 \%$.

In a first attempt, we directly compared the formal error estimates to the in situ absolute mismatch values. Ideally, these two values would show a positive correlation. Yet no 


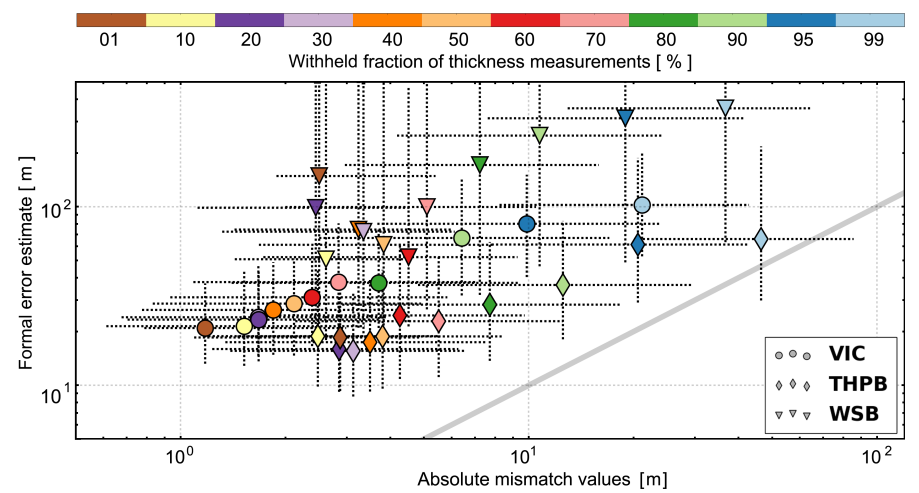

Figure 7. Median values for the absolute thickness mismatches and the error estimates at measurement locations not included during the reconstruction. Marker colours indicate the respective fraction of all measurements withheld from the reconstruction. Dashed crosses span the interquartile range of all mismatch values (horizontal) and all formal error estimates (vertical). For orientation, the identity line was added in grey.

clear dependence was discernible for any of the sample sizes. Both data distributions, for mismatch values and error estimates, are not normal. Being robust to outliers, we decided to quantify these distributions in terms of medians and quartiles (Fig. 7). In this aggregate sense, error estimates tend to overestimate the absolute mismatch. For small fractions of withheld measurements, the overestimation is stronger. This bias is not surprising as formal error estimates cannot fall below a preset measurement error (Sect. 3.9), whereas high correlation between thickness values at an adjacent location results in very low mismatch values. If only $1 \%$ of the measurements is withheld, median mismatch values do not exceed $3 \mathrm{~m}$, which simply reflects spatial data correlation. For this case, median error estimates are about $20 \mathrm{~m}$ for VIC and THPB. Error estimates are problematic on the stagnant WSB setup, where we find a median of $149 \mathrm{~m}$, which exceeds the mean ice thickness. For a withheld data fraction of $99 \%$, we find mismatch medians of $21 \mathrm{~m}$ for VIC, $47 \mathrm{~m}$ for THPB and $36 \mathrm{~m}$ for WSB. Again these are overestimated by the median error estimates of 102, 66 and $360 \mathrm{~m}$, respectively. Again the value on WSB stands out. We conclude that aggregated values of formal error estimates show a tendency to exceed mismatch values.

The above aggregate assessment suggested that the error estimates could serve as upper constraints for the actual mismatch. However, it remains unclear how reliable this interpretation is at individual measurement locations. We therefore compute the data fraction of all withheld measurements for which the actual mismatch is less than the predicted error estimate (Table 1). If only a $1 \%$ fraction of the measurements is withheld, more than $90 \%$ of the actual mismatch values fall into the error bounds. On VIC, even $100 \%$ is reached. As before, these high values simply reflect the strong spatial correlation in the measurements. Gradually withholding more data for validation, the data fraction for which the upper error constraints are valid decreases. The minimum of $64 \%$ is reached for THPB. These numbers give a first indication on the spatial reliability of the error-estimate map. Looking at the spatial distribution of violated error bounds (Fig. 6c and d), a clustering is visible for the ice-cap setup (VIC). We find violations along the land-terminating margin, where inferred thickness values tend to underestimate the measurements. Concerning violation in the interior, a tendency for overestimating the thickness values is discernible. For the more constrained valley glacier setups (THPB and WSB), these tendencies are not confirmed.

We conclude that median error estimates overestimate the mismatch values and could therefore serve as an upper error constraint. Accepting this interpretation, we can provide a maximum error range for aggregate quantities. Mean thickness values for VIC, THPB and WSB fall into a range of 172-320, 141-217 and 46-508 m, respectively. For the area fraction of ice grounded below sea level, we find ranges of $7-23 \%$ for VIC and $7-22 \%$ for THPB. The maximum range on VIC is clearly exceeded by the $5 \%$ area fraction inferred by a direct interpolation of measurements. Despite this aggregate assessment, the spatial reliability of interpreting the error-estimate map in terms of an upper constraint for local measurements becomes increasingly difficult the fewer measurements are available.

\subsection{Second-step reconstruction}

The second step of this reconstruction is applied in one subdomain for each test geometry, where velocity measurements exceed $100 \mathrm{~m} \mathrm{yr}^{-1}$ (Fig. $2 \mathrm{~g}$ and $\mathrm{h}$ ). In these sub-domains, mass conservation is directly solved for the unknown ice thickness. As this solution is additionally informed by velocity observations, we expect an improved thickness field. 

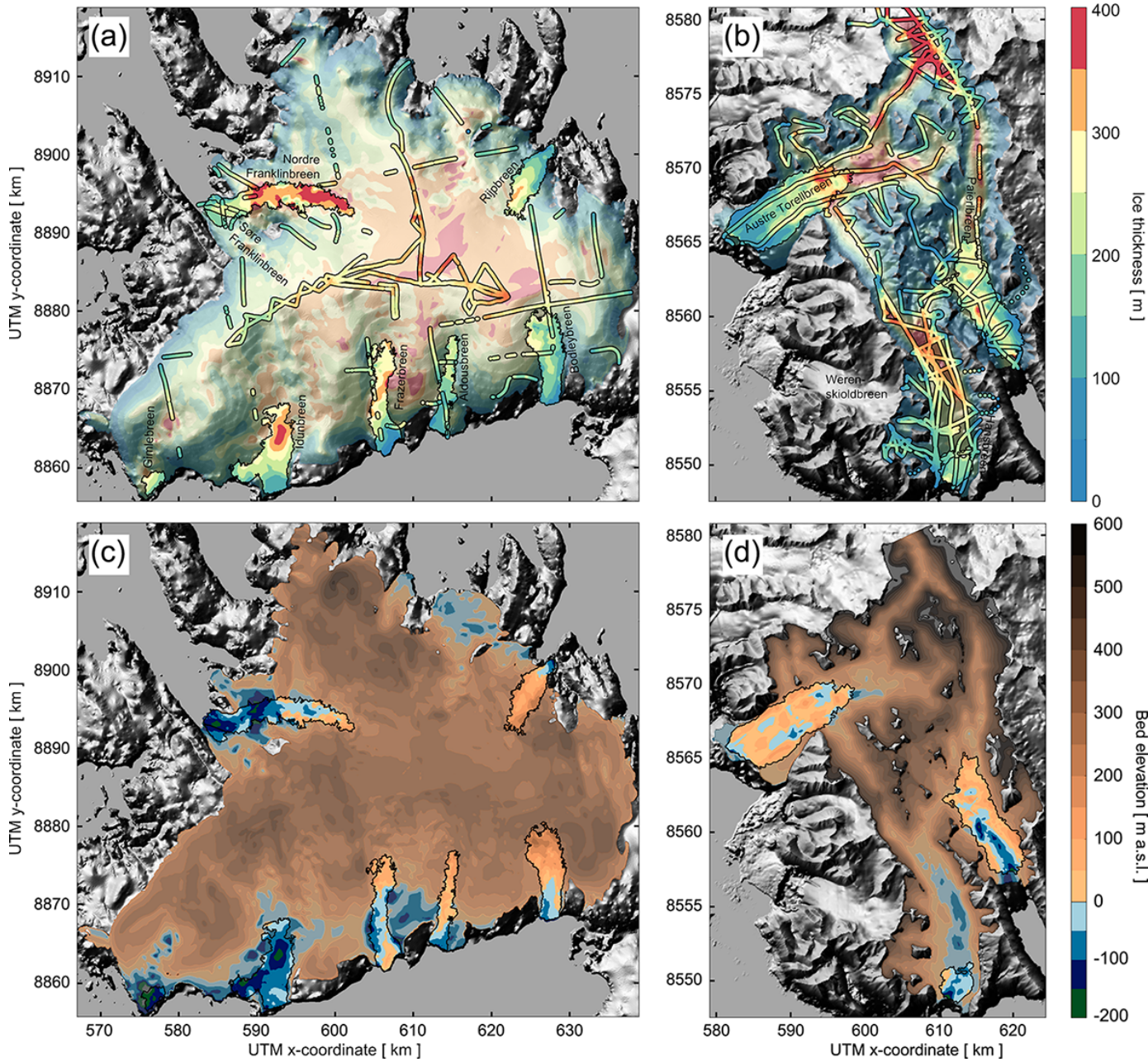

Figure 8. Ice thickness (a, b) as in Fig. 4 and associated bedrock topography (c, d) as in Fig. 5 for VIC (a, c) and THPB (b, d). Along the outlet glaciers (non-transparent lurid colours), the two fields were updated in the second-step accounting for velocity observations in the mass conservation. Partially transparent areas in these maps (unsaturated colours) stem from the first-step reconstruction, for which values are inferred from the flux solution.

\subsubsection{Ice thickness}

On VIC, ice thickness is updated along eight fast-flowing outlet glaciers (Fig. 8a and c). In these areas, the new thickness field can differ considerably from the first-step reconstruction (Fig. 4), particularly in areas with sparse observational constraints as for Idunbreen and Rijpbreen. The reason is that velocity streamlines deviate from the geometrically prescribed flux direction. Consequently, the ice is distributed differently. For Idunbreen and Rijpbreen, deeper troughs are found somewhat away from the ice front and a larger ice volume is inferred. For all other outlet glaciers, the ice volume estimate decreases. In addition, spurious along-flow variations in the geometrically controlled first-step thickness field, for instance on Bodleybreen and Rijpbreen (Fig. 4a), are not visible in the second-step field. Accounting for the secondstep reconstruction, both the total ice volume and the mean ice thickness slightly decrease to $538.8 \mathrm{~km}^{3}$ and $227 \mathrm{~m}$, re- spectively. The area fraction of ice grounded below sea level slightly reduces to $13.0 \%$.

In Wedel Jarlsberg Land, thickness fields are updated for the three fast-moving frontal areas of the THPB complex. The wealth of thickness observations implies that the firstand second-step reconstructions are very similar (Fig. 8b). This is certainly the case for Paierlbreen. Differences become largest near the calving fronts because of the free boundary condition. For Hansbreen, the bed trough near the ice front becomes both deeper and wider. For Austre Torellbreen, differences are more apparent as only two along-flow measurement profiles constrain the thickness field at low elevations. Along its centreline at the confluence with Vrangpeisbreen, an overdeepened spot in the first-step reconstruction is flattened in the updated basal topography (Fig. 8d). The frontal area is also thinner than in the first-step reconstruction. For 

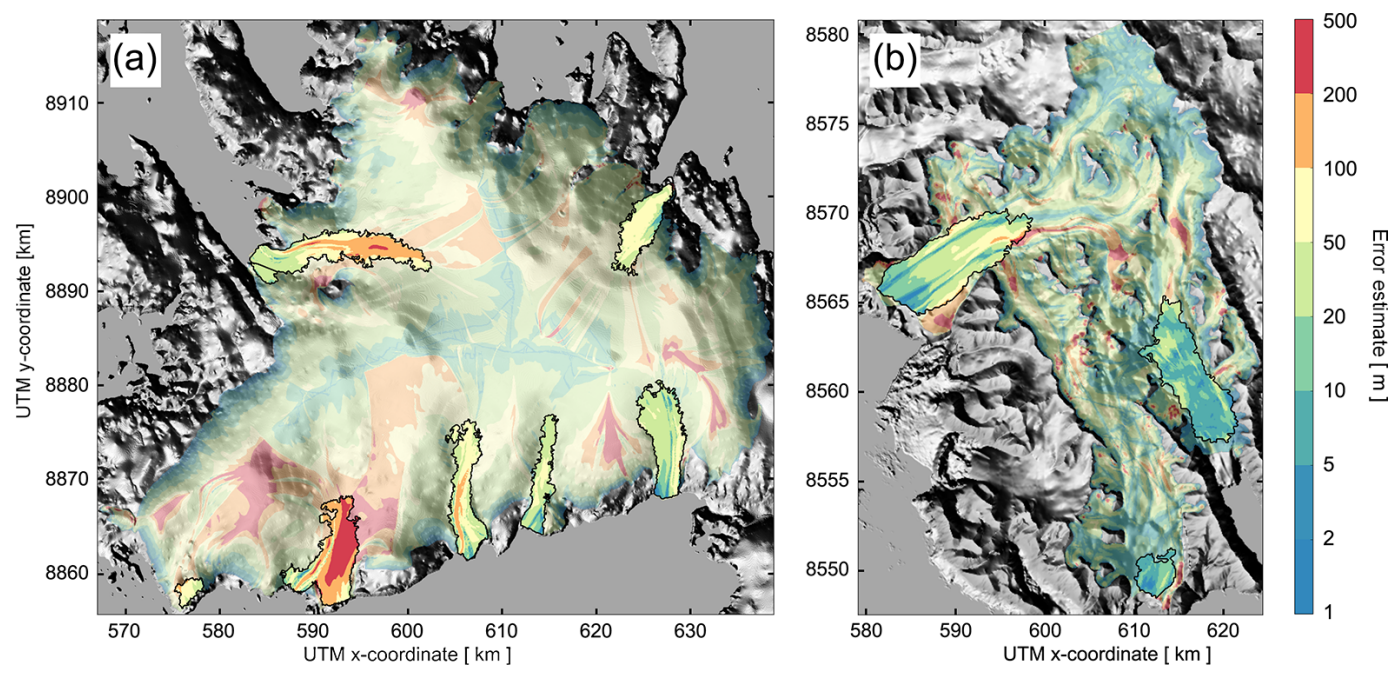

Figure 9. Error-estimate map as in Fig. 6 for VIC (a) and THPB (b). Partially transparent areas in the thickness maps (unsaturated colours) stem from the first-step reconstruction, for which ice thickness is inferred from the ice-flux solution. Along the outlet glaciers (non-transparent lurid colours), error estimates are updated relying on velocity observations (Fig. 2c and d).

the entire THPB complex, we find a small reduction of the average thickness to $173 \mathrm{~m}$.

\subsubsection{Mismatch and error estimates}

The updated error-estimate map (Fig. 9) is informed by firststep values at lateral boundaries. These estimates are now propagated along velocity streamlines, which themselves are inferred from measurements. On Frazerbreen and Hansbreen, large first-step error estimates near the ice front are reduced because of high velocities. In the sub-domains on VIC, magnitudes of the updated error estimates tend to increase as compared to the first-step values. A possible reason is the relatively large input velocity uncertainty of $20 \mathrm{~m} \mathrm{yr}^{-1}$.

We repeat the aggregate error assessment from above (Fig. 10). For VIC and THPB, we find that median mismatch values are higher than in the first step. So despite the additional velocity information, the second-step reconstruction is not necessarily able to produce a more reliable thickness map. Another trend is seen in the interquartile error-estimate range, which is often reduced, certainly for THPB. No trend is seen in the median error estimates between the first- and second-step reconstruction. Values reduce for THPB and increase for VIC as compared to the first step. Following the above interpretation of these aggregated error estimates in terms of a maximum range, we can update the mean thickness ranges to $171-320$ and $142-212 \mathrm{~m}$ for VIC and THPB, respectively. The maximum ranges for the area fraction below sea level become 6-23 and 6-18\%, respectively.

\section{General discussion}

In this section, we discuss the central assumptions and caveats of the presented reconstruction approach. For the first step, sliding is neglected, assuming that ice motion is an exclusive result from internal deformation. In areas without thickness and velocity information, this assumption is likely the dominant source of uncertainties and biases the results towards higher thickness values. Other reconstruction approaches use an empirical scaling relation (e.g. Farinotti et al., 2009b) or incorporate a transiently resolved relation for basal water availability (van Pelt et al., 2013). In either case, formulations are basic because of our limited knowledge of basal conditions. Although these approaches are valuable attempts to address the issue of unknown basal conditions, it remains questionable whether uncertainties in the reconstructed thickness field are in fact reduced. Here, we instead address basal sliding by relying on direct measurements of the surface velocities but limited to sub-domains where magnitudes exceed $100 \mathrm{~m} \mathrm{yr}^{-1}$. These velocity measurements comprise motion arising from both internal deformation and basal sliding. For THPB and VIC we find reduced values for the mean glacier thickness when using velocities. This concurs with the expected high bias in the first step.

Another caveat in the first-step reconstruction is the assumption that the ice flux follows a smoothed version of the surface-slope field (Sect. 2.2). The smoothing is spatially variable, accounting for non-local flow coupling via membrane stresses. Although the direction choice might be appropriate in slow-moving areas, the actual velocity vector can point elsewhere. The situation becomes even more complex for surging glaciers, for which the surface topography is notably modified during these short-term events. An exam- 


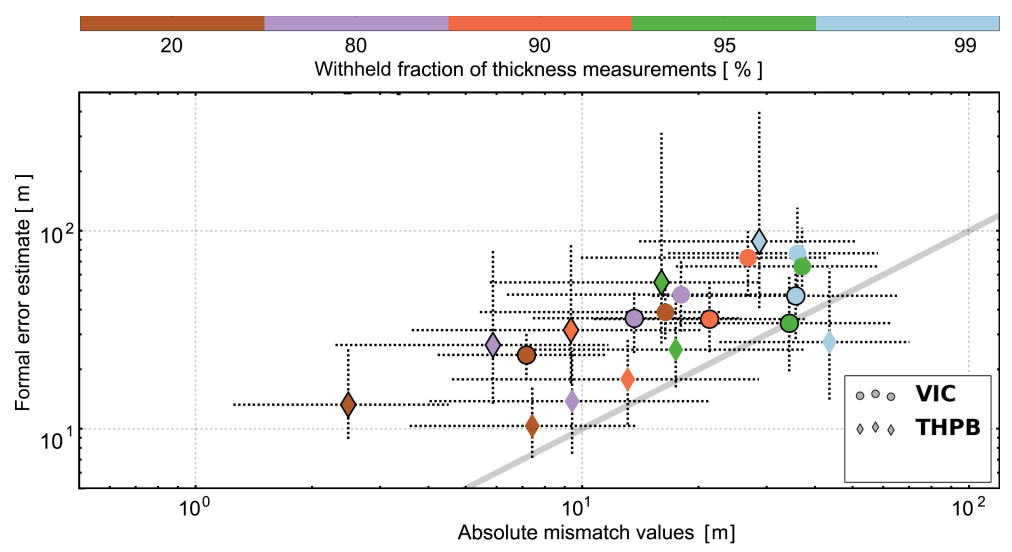

Figure 10. Median values for the absolute thickness mismatches and the error estimates as in Fig. (7). Values are only calculated within the sub-domains. Symbols with black edges represent the results from the first step. Symbols without edge line indicate the second-step results.

ples is Franklinbreen on VIC, for which velocity information from the early 1990s shows main outflow via the northern outlet branch. Using the 1990 DEM for the first-step reconstruction (Sect. C2), most ice is exported via the southern branch (not shown). Therefore, the surface topography is not necessarily the best indicator for the flow direction. In the second step, we were able to update the thickness field in consistency with the 2015-2016 velocity fields, with preferential outflow also via the southern branch. Yet even for this reconstruction, it is not evident how to account for important, non-regular dynamic changes, such as surging, as for instance on Franklinbreen and Paierlbreen (Błaszczyk et al., 2009).

The provided error-estimate map is shown to be a practical measure for a first error assessment. The underlying error analysis inherits all assumptions made in the massconserving reconstruction and thereby accounts for various input uncertainties. A fundamental assumption is that the error estimate is the minimum value of two solutions (Sect. 2.2.5). These two solutions stem from an error increase or an error decrease along the flow, both assumed to change at the same rate. We argue that the latter solution is necessary to constrain the error estimate upstream of measurements. However, the assumed magnitude of the decrease rate is disputable. Furthermore, the error analysis neglects other sources of uncertainty. First, not all input fields are contemporaneous, and therefore an inconsistency is introduced in the mass-conservation equation. Second, the control parameters $\dot{a}, u_{1}$ and $u_{2}$ are updated during the optimisation. These changes are unaccounted for in the constant input uncertainties. Third, input fields are time averaged. Such averaging suppresses seasonal signals for instance in the velocity measurements or is simply a necessity to obtain a climatologically meaningful SMB field. Yet the averaging adds further to the uncertainty. Finally, uncertainties in some SIA parameters and variables remain unconsidered, including surfaceslope magnitude and the viscosity parameter. The latter is even unconstrained if no thickness measurement is available. All these unconsidered source terms reduce the reliability of the presented error-estimate map. In a stringent Bayesian framework, Brinkerhoff et al. (2016) were able to account for many of the above terms.

Concerning the sensitivity of the thickness map of VIC to changes in the input SMB and the input DEM (Appendix C), we find that integrated values as mean ice thickness and ice volumes are rather insensitive. On VIC, relative differences in our analysis remain within $5 \%$ (Table C1). Differences in these integrated values reduce as more and more thickness measurements are available. Locally, differences can become large. Without thickness measurements for correction, an offset in the SMB directly translates into a thickness bias. Concerning the flux correction, relative differences in the total ice volume can reach $6 \%$, though most test cases show a smaller sensitivity below $3 \%$. For the ice-cap setup VIC, relative differences remain even smaller than $1 \%$. The central assumption in the second-step reconstruction is that surface velocities equal vertical mean values. This assumption is justified as this step is only applied in areas where surface velocities exceed $100 \mathrm{~m} \mathrm{yr}^{-1}$. There, basal sliding is likely dominant. An aggregate assessment of the thickness mismatch indicates that the second-step thickness update is not necessarily more reliable than the first step. Though the updated field is consistent with the actual flow field, mismatch values tend to be larger than in the first-step reconstruction. Reasons for a worse match are that velocity measurements also introduce further uncertainty and that thickness measurements enter as a cost term during the second step rather than being imposed in the first step. In addition, the sub-domain delineation might not be optimal.

\section{Conclusions}

We present a two-step, mass-conserving reconstruction approach to infer glacier thickness maps with prior knowledge 
on source and sink terms in the mass budget. The two steps guarantee applicability in absence of velocity measurements. In the first step, a glacier-wide thickness field is inferred from a balance flux calculation on the basis of an apparent mass balance field. The second step requires velocity measurements, which are often not reliable over an entire glacier drainage basin. Therefore, the glacier thickness is only updated over a sub-domain. This updated field is consistent with the observed flow field and shows a seamless transition into the glacier-wide first-step map. In both steps, available thickness measurements are readily assimilated to constrain the reconstruction. Moreover, the inferred thickness field is provided together with an error-estimate map, based on a formal propagation of input uncertainties. Here, we present and apply this approach to various glacier geometries on Svalbard where an abundant thickness record was available.

The approach is found to be most beneficial in areas where thickness observations are sparse or unavailable. There, our reconstruction is informed by the glacier geometry and the AMB. Direct interpolations of thickness measurements often ignore this geometric and climatic information and fill a gaps according to distant measurements. The associated error map estimated from our reconstruction additionally highlights areas with least constrained ice thickness, namely away from observations and especially where ice flow is small or even stagnates. In an aggregate, glacier-wide sense, the actual thickness mismatch is shown to reach $25 \%$ for glaciers with only few thickness measurements. In absence of such measurements, the aggregate mismatch freely scales with a priori choices for not-well-constrained parameters.
In light of the growing body of information on glacier changes with satellite remote sensing, reconstruction approaches for mapping glacier ice thickness are less and less limited from the input side. Therefore, 2-D approaches become increasingly attractive and favourable because a final interpolation, which fills gaps between reconstruction profiles, can be avoided. However, the largest limitation on the applicability of 2-D approaches is the availability of regional information on surface elevation changes and surface mass balance. Elevation change maps from satellite remote sensing have already been presented for several regions but further development is necessary to reduce uncertainties associated with signal penetration and firn properties. Concerning regional SMB fields, we can either rely on parametric approaches or on regional climate models. In absence of both SMB and $\partial_{t} h$, a most basic parametric AMB approach has already been forwarded to infer distributed thickness fields worldwide (Huss and Farinotti, 2012).

Data availability. The data can be requested from the corresponding author. In the near future, we will provide consistent Svalbardwide fields for ice thickness and error estimates via one of the common online repositories. 


\section{Appendix A: Viscosity parameter}

To translate the ice-flux solution into an ice-thickness field, the ice-viscosity parameter $B$ has to be defined (Fig. A1). Parameter values are inferred at locations where thickness measurements are available via Eq. (7). The resultant point information is then interpolated over the entire glacier domain (Sect. 2.2.4). For VIC, we find values covering a spectrum from 0.02 to $0.55 \times 10^{6} \mathrm{~Pa} \mathrm{yr}^{1 / 3}$, which corresponds to a rate-factor range from $1.90 \times 10^{-25}$ to $3.07 \times 10^{-21} \mathrm{~Pa}^{-3} \mathrm{~s}^{-1}$. For ice temperatures between -20 and $0^{\circ} \mathrm{C}$, we would expect rate-factor values between $1.0 \times 10^{-25}$ and $2.4 \times 10^{-24} \mathrm{~Pa}^{-3} \mathrm{~s}^{-1}$ (e.g. p. 75 , in Cuffey and Paterson, 2010). The inferred values for VIC clearly exceed this meaningful range and should therefore not be interpreted in terms of a material property. The ice viscosity is a tuning factor, which compensates for any assumptions in the reconstruction or deficiencies and inconsistencies of input fields. The parameter is further aliased by not accounting for basal sliding. The highest viscosities are inferred in areas next to land-terminating boundaries. These areas are also characterised by small flux values. As observations show some non-negligible thickness values there, $B$ has to be high. The lowest values are seen in the northern part of the ice cap and along the lower trunk of Aldousbreen. For this glacier, one might interpret these low values in terms of sliding. However, for other outlet glaciers, the viscosity parameter is not necessarily decreased as compared with the surrounding area. This inconsistency also suggests that a physical interpretation of the viscosity parameter is delicate.
For the THPB and WSB area, the $B$-field also shows strong variations (Fig. A1). Values cover a range from 0.02 to $2.20 \times 10^{6} \mathrm{~Pa} \mathrm{yr}^{1 / 3}$, corresponding to a rate factor range between $2.97 \times 10^{-27}$ and $2.28 \times 10^{-21} \mathrm{~Pa}^{-3} \mathrm{~s}^{-1}$. The inferred range is even larger than for VIC and again exceeds the physical range. Yet for these glaciers, a pattern might be discernible. High viscosities are often concentrated along central glacier flow lines. One explanation could be that the flux solution shows a low bias along these trunks as a result of systematic inconsistencies between the input SMB and the surface elevation changes. Such a systematic effect would naturally cumulate as ice flow converges towards centrelines. Lowest viscosity values are concentrated along the ridges and in the flat area between the nunataks separating Paierlbreen and Austre Torellbreen.

In summary, the interpretation of the viscosity field $B$ in terms of ice dynamics is rather limited because values exceed the physical range. The field should rather be seen as a multiplier for tuning purposes as it can compensate for uncertainties in and inconsistencies between input fields as well as for assumptions within this first-step reconstruction. $B$ is presented here to visualise that a single viscosity parameter might not be sufficient to capture all spatial variations in the thickness field. Initially, a best-fit single viscosity value over entire drainage basins was used, but the thickness pattern could not be explained by variations in ice flux and surface slopes alone (Eq. 7). A single viscosity parameter resulted in underestimated ice thickness for the thick parts of the glacier and overestimated values for shallower parts (not shown). Other comparable state-of-the-art approaches often use a constant value for entire glacier basins (Farinotti et al., 2009b; Huss and Farinotti, 2012; van Pelt et al., 2013).
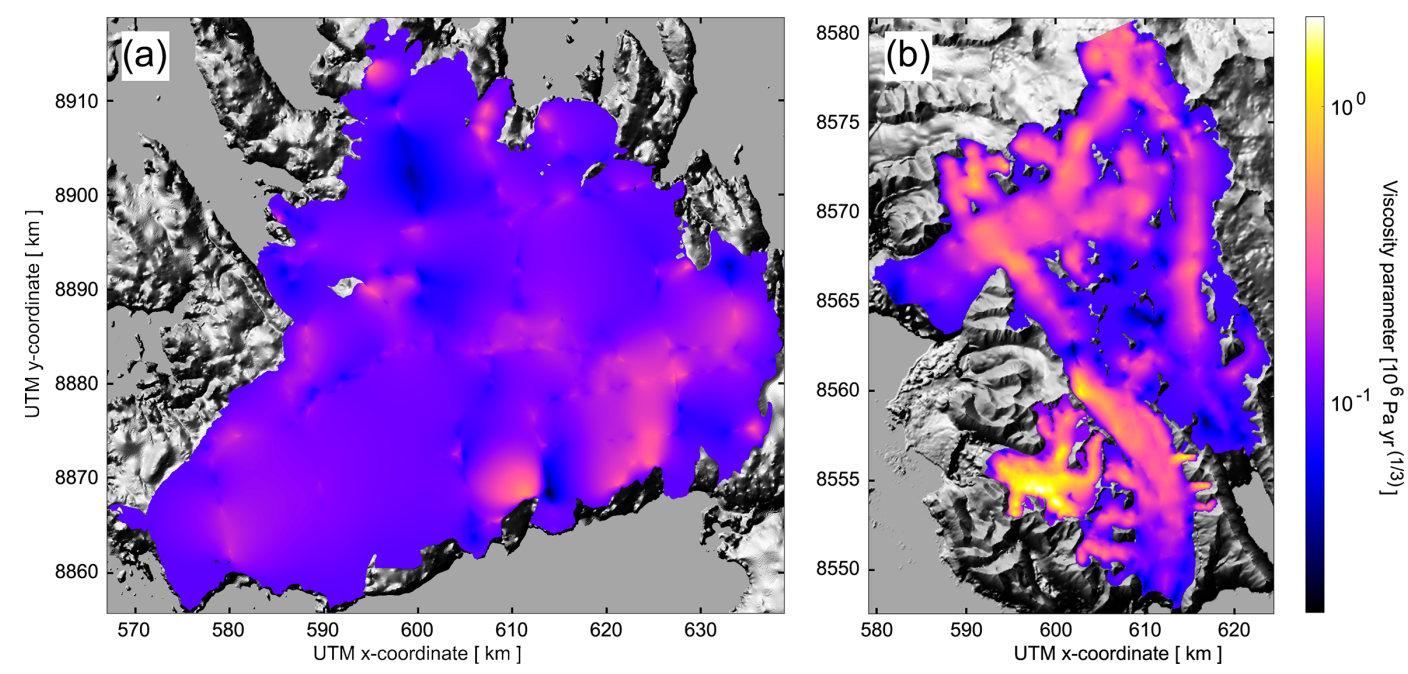

Figure A1. The ice-viscosity parameter $B$ for VIC (a), THPB and WSB (b) is inferred during the first step of the reconstruction as explained in Sect. 2.2.4. This parameter is used to match observed and reconstructed thickness values. An interpretation in terms of material property is delicate because the parameter compensates for input uncertainties and inconsistencies as well as for assumptions in the first-step reconstruction. Background: grey-scale hill-shaded topography based on a NPI 50 m DEM (http://publicdatasets.data.npolar.no/kartdata/NP_S0_ DTM50.zip). 


\section{Appendix B: Apparent mass balance}

In this section, we will briefly discuss how the AMBfield $\dot{a}$ is adapted during the first-step optimisation when all thickness measurements are taken into account (Figs. 2e, $\mathrm{f}$ and B1). On the ice cap geometry, differences between the initial and the final AMB field are most expressed along the ice divide, along other ridges and along some centrelines, as for instance on Frazerbreen. The reason for pronounced changes along these features is that they are focal areas in terms of flux convergence or divergence. AMB modifications there can efficiently correct for flux deficiencies (as defined by the cost function) over a large area of influence (either up- or downstream). The initial AMB shows only negative values over the little ice dome feeding Forsiusbreen. Yet after optimisation a small source area was created, which explains the presence of ice in this area. Despite these most pronounced changes, the average AMB over the ice cap is initially $0.02 \mathrm{~m} \mathrm{yr}^{-1}$ while finally we find $0.03 \mathrm{~m} \mathrm{yr}^{-1}$. This is an increase of $35 \%$. For WSB, even the sign of the AMB average changes as initially the main branch of the glacier shows hardly any source region with positive AMB. As ice flux is expected to be positive and as no inflow is possible along the upper land-terminated margin, the optimisation guides the system to a more equilibrated AMB state over this glacier. For THPB, the input AMB shows an area average of $4.1 \mathrm{~m} \mathrm{yr}^{-1}$, differing by less than one per mille from the final average. For THPB, differences between the final and the initial AMB field are again most expressed along certain flow lines.
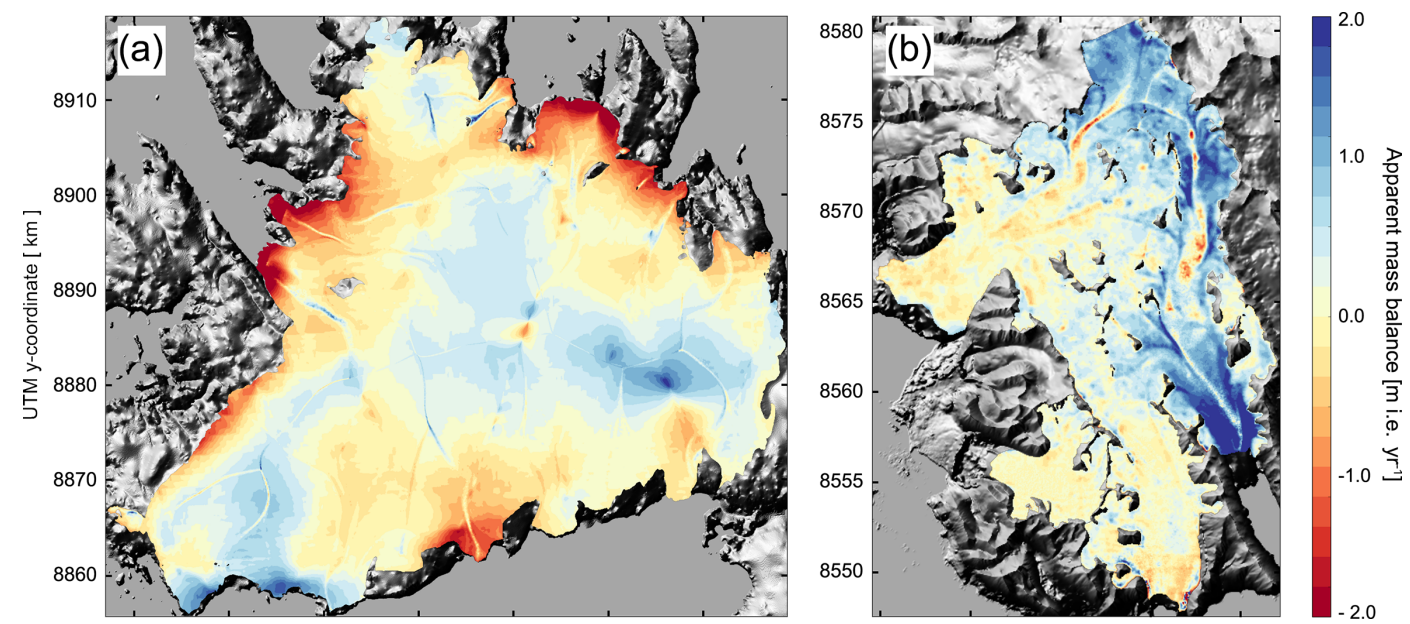

Figure B1. Final apparent mass balance $\dot{a}$ for VIC (a), THPB and WSB (b) after minimisation of the cost function. During this minimisation, $\dot{a}$ is iteratively adjusted. The input values of $\dot{a}$ are presented in Fig. 2e and f. Background: grey-scale hill-shaded topography based on a NPI 50 m DEM (http://publicdatasets.data.npolar.no/kartdata/NP_S0_DTM50.zip). 


\section{Appendix C: Sensitivity analysis}

\section{C1 Surface mass balance}

Here, the sensitivity of the first-step reconstruction to the SMB input is briefly discussed for VIC (Fig. 8). For this purpose, we exchange the 1975-2015 MAR-SMB with the 2003-2013 WRF-SMB (Sect. 3.5). A fundamental discrepancy between the simulated time periods becomes apparent when integrating the SMB fields over the ice cap. We obtain mean SMB values of -0.08 for MAR and $-0.3 \mathrm{~m}$ i.e. $\mathrm{yr}^{-1}$ per unit area for WRF. For the WRF-SMB, more ice is removed at low elevations consistent with the warmer climatic conditions of the more recent period. When using all thickness measurements, the new thickness field (Fig. C1a) is very similar (Fig. 4a), showing a slightly reduced mean value of $225 \mathrm{~m}$ as compared to $228 \mathrm{~m}$ (Table $\mathrm{C} 1$ ). Consequently, the new volume estimate is also reduced to $531.9 \mathrm{~km}^{3}$ (about $2 \%$ ). Reduced thickness values are best discernible near the ice fronts of Gimlebreen, Idunbreen and Bodleybreen. Due to a lack of observations in these regions, the reconstruction is not well constrained, and, as the WRF-SMB removes more ice, glacier thickness estimates become smaller. This reduction is important as the ice cliff height determines the unknown ice discharge. The frontal reduction is less clear for the land-terminating margin because steeper surface slopes limit the ablation-zone extent. The reduction becomes even more evident when only $1 \%$ of the thickness measurements is used (Fig. C1b). However, thickness values near the ice divide are not necessarily smaller. On average, the ice volume estimate is reduced to $515.9 \mathrm{~km}^{3}$ and a mean thickness value of $218 \mathrm{~m}$ is found (as compared to $230 \mathrm{~m}$ ). In general, the reconstruction is capable of compensating poorly constrained SMB data where the thickness record has good spatial coverage.

\section{C2 Surface topography}

The sensitivity of the first-step thickness field to the DEM choice is smaller as compared to the SMB sensitivity. The exchange of the 2010 DEM (Sect. 3.3) with the NPI 1990 DEM results in a relative thickness and ice-volume difference of less than $1.3 \%$ (Table C1). Maximum thickness values increase slightly. The new thickness field is comparably smooth because the NPI DEM on VIC was computed from contour line information. As a consequence, some patterns change in the reconstructed ice-thickness map (Fig. C2). One more prominent difference is that the lower trunk of Franklinbreen becomes more elongate and deep. Pattern differences are again more expressed in the case when less thickness observations are used. Locally, thickness differences can become very high. Therefore, the DEM choice is important for a reliable reconstruction. However, volume differences are relatively small $(<1.3 \%)$ as compared to ex- pected mismatch values of more than $25 \%$, if no observations were available.

\section{C3 Negative ice flux}

On VIC and THPB, the area fraction with negative ice flux is 1.2 and $3.1 \%$, respectively. On WSB, however, the flux solution over the main branch is generally very small and shows many zero transitions. Consequently, the area-fraction is higher at $4.1 \%$. The reason is that the AMB shows no dominant source area in the upper glacier ranges. The zero transitions in the flux solution would directly transmit into the ice-thickness field. To avoid such transitions, we correct the flux as follows:

$F^{*}=(1-\kappa) \cdot\|F\|+\kappa \cdot F_{\text {crit }}$, with

$\kappa=1-2 / \pi \cdot \operatorname{atan}\left(F^{2} / F_{\text {crit }}^{2}\right)$.

The exact functional dependence for $\kappa$ is not decisive but the choice has to assure a smooth transition. $F_{\text {crit }}$ is set to $10 \%$ of the average flux magnitude over the domain. This value proved reasonable for the WSB setup. For smaller values, the flux field in the vicinity of negative values is less and less affected, resulting in a more abrupt transition. Along the lateral land-terminating domain margin, we keep $F=F^{*}=0$. When thickness measurements are available, the effect of this flux correction on the inferred thickness is compensated by the calculation of the ice viscosity. Without measurements and for $F>F_{\text {crit }}$, the functional dependence implies that the reduction effect on the inferred thickness field remains below $2 \%$. Where flux magnitudes exceed the domain average $\left(10 \times F_{\text {crit }}\right)$, the effect on the ice thickness falls below $0.15 \%$. For $F<F_{\text {crit }}$, thickness values are effectively increased.

The flux correction applied during the first-step reconstruction (Sect. 2.2.4) could be considered an important bias. Note, however, that the correction is not added to the flux solution itself (Fig. 3) and that it does not enter the error calculations (Sect. 2.2.5). The correction is only applied when inferring ice-thickness values for the purpose of avoiding zero transitions in areas where flux values turn negative. In this way, it only affects the ice thickness and the viscosity parameter. Where negative values occur, the flux solution and the geometrically imposed flux direction cannot be reconciled. The negative values prevail despite the penalty in the cost function during the optimisation (Sect. 2.2.3). An increase of the respective multiplier in the cost function resulted only in a limited improvement on WSB and came at the expense of a more variable flux field on all geometries. Therefore, we instead decided to introduce a correction term that guarantees positive flux values in the SIA equation (Eq. 7). The correction is primarily required for WSB, for which magnitudes of the flux solution are very small. Nevertheless, we applied it to all geometries to keep a uniformity approach.

The first-step thickness solution is most sensitive to the flux correction in small areas along divides and ridges 
(Fig. C3). For VIC, streak features with small thickness values appear for instance on Bragebreen (in the southwest) and northeast of Bodleybreen. Similar features are difficult to discern for THPB. More prominent are the effects on WSB. There, a noise pattern of near-zero values appears for the thickness field of the main trunk where flux values are small (Fig. 3). The bogus noise pattern is not acceptable as we expect that the thickness field shows more gradual changes. For VIC, relative differences in ice volume and mean ice thickness remain below $1 \%$ (Table $\mathrm{C} 1$ ). When all available thickness measurements are considered, these relative differences do not exceed $2.5 \%$ for all our test geometries. If the reconstruction is badly informed by only $1 \%$ of all measurements, the value increases to $5.8 \%$ on THPB, while it does note exceed $1 \%$ for the VIC and WSB. The flux correction does not introduce a preference for either reducing or increasing the mean ice thickness.

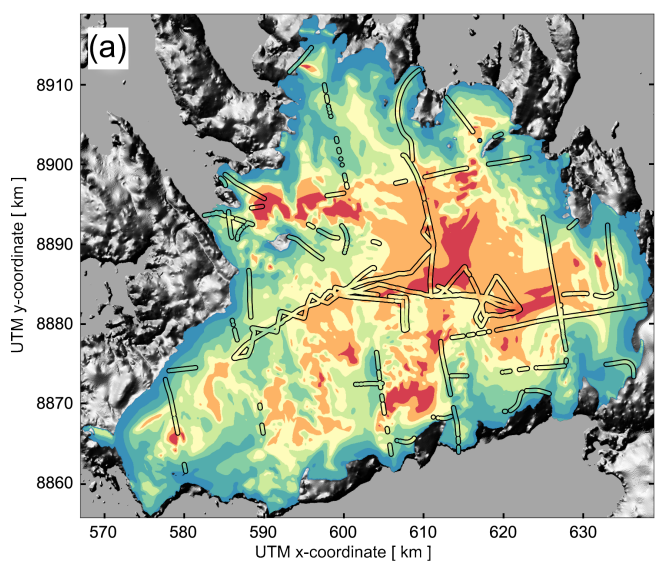

In summary, the effect of the flux correction can lead to a considerable difference in ice volume in the cases where no thickness measurements are available and where small flux values prevail over a large area. Yet, where measurements are available, a compensation is possible via the ice-viscosity parameter $B$. The effect of the flux correction is expected to be largest for stagnating glaciers, whereas for dynamically active glaciers, consequences will be negligible. The ice-flux field gives an indication on whether consequences are expected to be large and where they will be most expressed. In any case, the error-estimate map will highlight areas where the correction is most important. For the main trunk of WSB, error estimates exceed by far the inferred thickness values (Fig. 6b).

Figure C1. Ice-thickness map for VIC as in Fig. 4 based on the 2003-2013 WRF-SMB field using all (a) or only $1 \%$ (b) of the thickness

measurements.
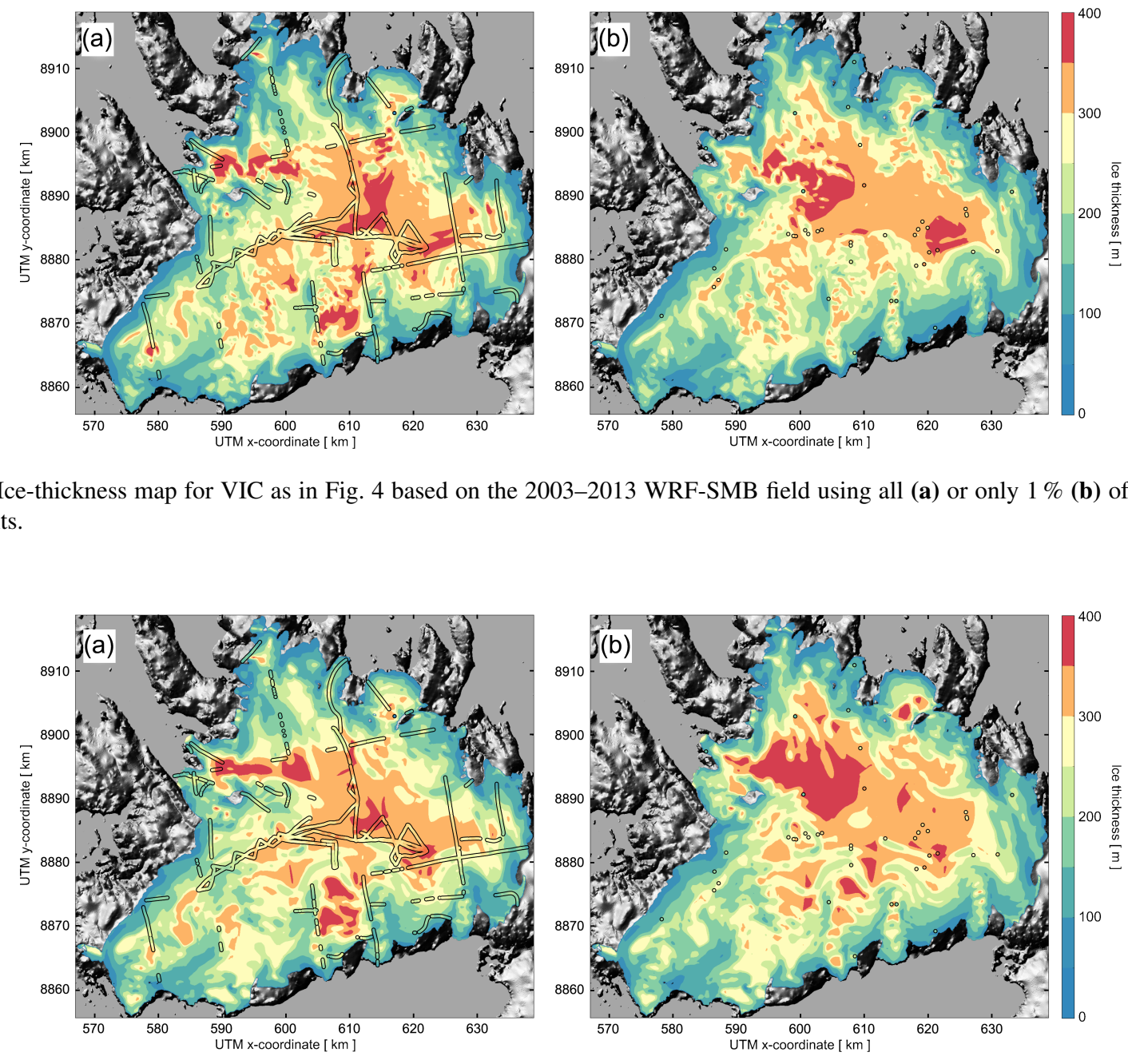

Figure C2. Ice-thickness map for VIC as in Fig. 4. Here, the reconstruction is conducted with the NPI $50 \mathrm{~m}$ (http://publicdatasets.data.npolar. no/kartdata/NP_S0_DTM50.zip) as surface topography using either all (a) or only $1 \%$ (b) of the thickness measurements. 

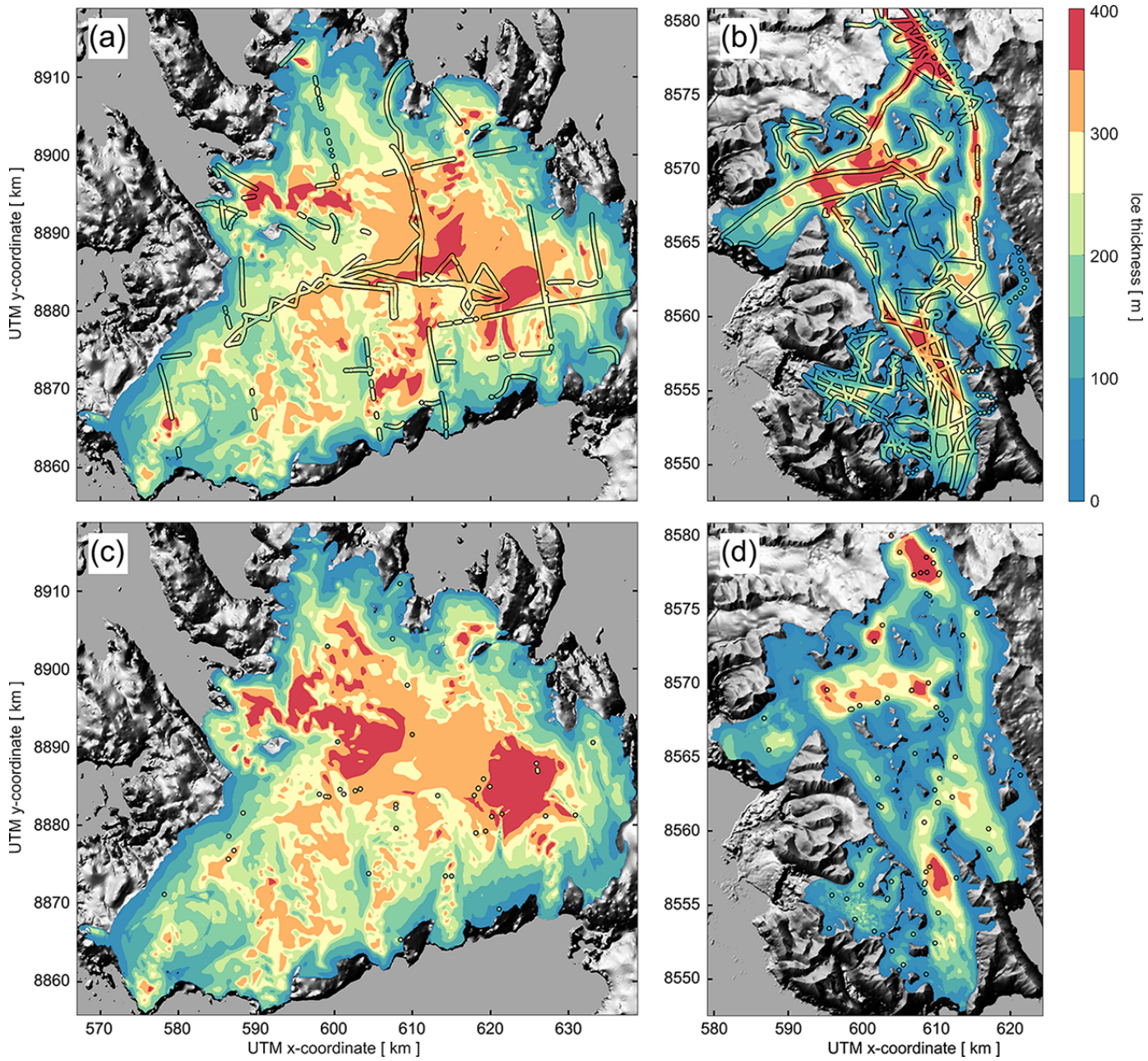

Figure C3. Ice thickness for VIC (a, c), THPB and WSB (b, d) as in Fig. 4. Here, the first-step SIA thickness field is not corrected for negative flux values (Sect. 2.2.4). For WSB, many spots appear in central areas where ice thickness is very small. These bogus variations are a consequence of zero transitions in the flux field. For VIC and THPB such bogus variations are limited to some few small areas.

Table C1. Reconstruction sensitivity as quantified by the mean and maximum ice thickness, the ice volume and the area fraction grounded below sea level. The \$symbol separates values stemming from a reconstruction using either all or only a $1 \%$ fraction of the available thickness measurements.

\begin{tabular}{llccrr}
\hline Setting & $\begin{array}{l}\text { Glacier } \\
\text { geometry } \\
\text { abbreviation }\end{array}$ & $\begin{array}{c}\text { Mean } \\
\text { thickness } \\
(\mathrm{m})\end{array}$ & $\begin{array}{c}\text { Maximum } \\
\text { thickness } \\
(\mathrm{m})\end{array}$ & $\begin{array}{r}\text { Ice volume } \\
\left(\mathrm{km}^{3}\right)\end{array}$ & $\begin{array}{c}\text { Area fraction } \\
\text { below sea level } \\
(\%)\end{array}$ \\
\hline Reference & VIC & $228.3 \ddagger 229.6$ & $448.5 \ddagger 452.7$ & $540.2 \ddagger 543.3$ & $13.3 \ddagger 13.4$ \\
& THPB & $175.7 \ddagger 145.3$ & $611.1 \ddagger 563.6$ & $53.5 \ddagger 44.3$ & $12.2 \ddagger 7.84$ \\
& WSB & $112.1 \ddagger 100.3$ & $279.0 \ddagger 210.8$ & $3.00 \ddagger 2.68$ & $0.25 \ddagger 0.08$ \\
\hline WRF-SMB & VIC & $224.8 \ddagger 218.0$ & $467.0 \ddagger 424.7$ & $531.9 \ddagger 515.9$ & $12.0 \ddagger 10.2$ \\
NPI 50 m DEM & VIC & $225.5 \ddagger 230.5$ & $451.0 \ddagger 475.7$ & $533.6 \ddagger 545.5$ & $12.5 \ddagger 13.0$ \\
\hline No flux correction & VIC & $227.8 \ddagger 231.6$ & $580.1 \ddagger 563.1$ & $538.9 \ddagger 547.9$ & $13.2 \ddagger 13.2$ \\
& THPB & $171.5 \ddagger 136.9$ & $609.5 \ddagger 563.5$ & $52.3 \ddagger 41.7$ & $12.4 \ddagger 7.84$ \\
& WSB & $114.5 \ddagger 100.9$ & $412.9 \ddagger 265.8$ & $3.06 \ddagger 2.70$ & $0.17 \ddagger 0.20$ \\
\hline
\end{tabular}


Author contributions. JJF designed and implemented the reconstruction approach, applied it to the test cases and elaborated the details of the error estimation. The research aims and setup were developed in regular discussion with FG-C, TS, BS and MB. JJF led the writing of the manuscript, in which he received support from all authors. FG-C developed and provided the initial version of the optimisation routines. Input fields for the reconstruction are the Sentinel-1 surface velocities from TS; ice-thickness measurements from TJB, JAD, RP, FN and MG; DEMs from CN and BS; surface elevation changes from $\mathrm{CN}$ and $\mathrm{GM}$; and surface mass balance fields from XF, CL and KA.

Competing interests. The authors declare that they have no conflict of interest.

Acknowledgements. This study received primary funding from the German Research Foundation (DFG) under grant number FU1032/1-1. Results presented in this publication are based on numerical simulations conducted at the high-performance computing centre of the Regionales Rechenzentrum Erlangen (RRZE) of the University of Erlangen-Nuremberg. The reconstruction approach also benefits from co-development work of the Elmer/Ice team at the CSC-IT Center for Science Ltd. (Finland). The velocity analysis on Svalbard was funded by DFG within the priority programme 1158 Antarctic Research with Comparable Investigations in Arctic Sea Ice Areas under contract number BR2105/9-1 and received financial support from the Helmholtz Association of the German Research Centres (HGF) Alliance on Remote Sensing and Earth System Dynamics. Thickness data collection in Wedel Jarlsberg Land was funded by the Spanish R \& D projects C11093001 and C150954001, NCBiR/PolarCLIMATE-2009/2-2/2010 from the Polish National Centre for R\&D, by IPY/269/2006 from the Polish Ministry of Science and Higher Education, by Polish-Norwegian funding through the AWAKE (PNRF-22-AI-1/07) project, by the EU FP7 ice2sea programme (grant number 226375) and by funds of the Leading National Research Centre (KNOW) received by the Centre for Polar Studies of the University of Silesia, Poland. The DEM generation in Wedel Jarlsberg Land received financial support from the European Research Council (grant 320816) and from ESA (project Glaciers CCI, 4000109873/14/I-NB). TanDEM-X data were provided under AO XTIGLAC6770. The WRF-SMB field was produced within the PERMANOR project funded by the Norwegian Research Council (255331).

Edited by: Andreas Vieli

Reviewed by: Fabien Maussion and Douglas Brinkerhoff

\section{References}

Aas, K., Dunse, T., Collier, E., Schuler, T., Berntsen, T., Kohler, J., and Luks, B.: The climatic mass balance of Svalbard glaciers: a 10-year simulation with a coupled atmosphereglacier mass balance model, The Cryosphere, 10, 1089-1104, https://doi.org/10.5194/tc-10-1089-2016, 2016.
Atwood, D. K., Meyer, F., and Arendt, A.: Using L-band SAR coherence to delineate glacier extent, Can. J. Remote Sens., 36, S186-S195, https://doi.org/10.5589/m10-014, 2010.

Berthier, E., Schiefer, E., Clarke, G., and Menounos, B.: Contribution of Alaskan glaciers to sea-level rise derived from satellite imagery, Nat. Geosci., 3, 92-95, https://doi.org/10.1038/ngeo737, 2010.

Berthier, E., Cabot, V., Vincent, C., and Six, D.: Decadal RegionWide and Glacier-Wide Mass Balances Derived from MultiTemporal ASTER Satellite Digital Elevation Models. Validation over the Mont-Blanc Area, Front. Earth Sci., 4, 1-16, https://doi.org/10.3389/feart.2016.00063, 2016.

Bishop, M., Olsenholler, J., Shroder, J., Barry, R., Raup, B., Bush, A., Copland, L., Dwyer, J., Fountain, A., Haeberli, W., Kääb, A., Paul, F., Hall, D., Kargel, J., Molnia, B., Trabant, D., and Wessels, R.: Global Land Ice Measurements from Space (GLIMS): Remote Sensing and GIS Investigations of the Earth's Cryosphere, Geocarto Int., 19, 57-84, https://doi.org/10.1080/10106040408542307, 2004.

Błaszczyk, M., Jania, J., and Hagen, J.: Tidewater glaciers of Svalbard: Recent changes and estimates of calving fluxes, Polish Polar Res., 30, 85-142, 2009.

Błaszczyk, M., Jania, J., and Kolondra, L.: Fluctuations of tidewater glaciers in Hornsund Fjord (Southern Svalbard) since the beginning of the $20^{\text {th }}$ century, Polish Polar Res., 34, 327-352, https://doi.org/10.2478/popore?2013?0024, 2013.

Braun, M., Pohjola, V., Pettersson, R., Möller, M., Finkelnburg, R., Falk, U., Scherer, D., and Schneider, C.: Changes of glacier frontal positions of Vestfonna (Nordaustlandet, Svalbard), Geograf. Ann. A, , 93, 301-310, https://doi.org/10.1111/j.14680459.2011.00437.x, 2011.

Brinkerhoff, D. and Johnson, J.: A stabilized finite element method for calculating balance velocities in ice sheets, Geosci. Model Dev., 8, 1275-1283, https://doi.org/10.5194/gmd-8-1275-2015, 2015.

Brinkerhoff, D. J., Aschwanden, A., and Truffer, M.: Bayesian Inference of Subglacial Topography Using Mass Conservation, Front. Earth Sci., 4, 1-15, https://doi.org/10.3389/feart.2016.00008, 2016.

Brooks, A. and Hughes, T.: Streamline upwind/Petrov-Galerkin formulations for convection dominated flows with particular emphasis on the incompressible Navier-Stokes equations, Comput. Meth. Appl. Mech. Eng., 32, 199-259, https://doi.org/10.1016/0045-7825(82)90071-8, 1982.

Carrivick, J., Davies, B., James, W., Quincey, D., and Glasser, N.: Distributed ice thickness and glacier volume in southern South America, Global Planet. Change, 146, 122-132, https://doi.org/10.1016/j.gloplacha.2016.09.010, 2016.

Clarke, G., Berthier, E., Schoof, C., and Jarosch, A.: Neural Networks Applied to Estimating Subglacial Topography and Glacier Volume, J. Climate, 22, 2146-2160, https://doi.org/10.1175/2008JCLI2572.1, 2009.

Clarke, G., Anslow, F., Jarosch, A., Radić, V., Menounos, B., Bolch, T., and Berthier, E.: Ice Volume and Subglacial Topography for Western Canadian Glaciers from Mass Balance Fields, Thinning Rates, and a Bed Stress Model, J. Climate, 26, 4282-4303, https://doi.org/10.1175/JCLI-D-12-00513.1, 2013.

Cuffey, K. and Paterson, W.: The Physics of Glaciers, ButterworthHeinemann publications, Elsevier, Oxford, UK, 2010. 
Dowdeswell, J.: Drainage-basin characteristics of Nordaustlandet ice caps, Svalbard, J. Glaciol., 32, 31-38, 1986a.

Dowdeswell, J.: Remote sensing of ice cap outlet glacier fluctuations on Nordaustlandet, Svalbard, Polar Res., 4, 25-32, $1986 \mathrm{~b}$.

Dowdeswell, J.: On the nature of Svalbard icebergs, J. Glaciol., 35, 224-234, 1989.

Dowdeswell, J. and Collin, R.: Fast-flowing outlet glaciers on Svalbard ice caps, Geology, 18, 778-781, 1990.

Dowdeswell, J., Drewry, D., Cooper, A., and Gorman, M.: Digital mapping of the Nordaustlandet ice caps from airborne geophysical investigations, Ann. Glaciol., 8, 51-58, https://doi.org/10.1175/2010JCLI3656.1, 1986.

Fahnestock, M., Scambos, T., Moon, T., Gardner, A., Haran, T., and Klinger, M.: Rapid large-area mapping of ice flow using Landsat 8, Remote Sens. Environ., 185, 84-94, https://doi.org/10.1016/j.rse.2015.11.023, 2016.

Fan, Q., Efrat, A., Koltun, V., Krishnan, S., and Venkatasubramanian, S.: Hardware-assisted Natural Neighbor Interpolation, in: Proc. 7th Workshop on Algorithm Engineering and Experiments (ALENEX), 22 January 2005, Vancouver, BC, Canada, 111-120, 2005

Farinotti, D., Huss, M., Bauder, A., and Funk, M.: An estimate of the glacier ice volume in the Swiss Alps, Global Planet. Change, 68, 225-231, https://doi.org/10.1016/j.gloplacha.2009.05.004, 2009a.

Farinotti, D., Huss, M., Bauder, A., Funk, M., and Truffer, M.: A method to estimate the ice volume and icethickness distribution of alpine glaciers, J. Glaciol., 55, 422-430, https://doi.org/10.3189/002214309788816759, 2009 b.

Farinotti, D., Brinkerhoff, D., Clarke, G., Fürst, J., Frey, H., Gantayat, P., Gillet-Chaulet, F., Girard, C., Huss, M., Leclercq, P., Linsbauer, A., Machguth, H., Martin, C., Maussion, F., Morlighem, M., Mosbeux, C., Pandit, A., Portmann, A., Rabatel, A., Ramsankaran, R., Reerink, T., Sanchez, O., Stentoft, P., Singh Kumari, S., van Pelt, W., Anderson, B., Benham, T., Binder, D., Dowdeswell, J., Fischer, A., Helfricht, K., Kutuzov, S., Lavrentiev, I., McNabb, R., Gudmundsson, G., Li, H., and Andreassen, L.: How accurate are estimates of glacier ice thickness? Results from ITMIX, the Ice Thickness Models Intercomparison eXperiment, The Cryosphere, 11, 949-970, https://doi.org/10.5194/tc-11-949-2017, 2016.

Farr, T., Rosen, P., Caro, E., Crippen, R., Duren, R., Hensley, S., Kobrick, M., Paller, M., Rodriguez, E., Roth, L., Seal, D., Shaffer, S., Shimada, J., Umland, J., Werner, M., Oskin, M., Burbank, D., and Alsdorf, D.: The Shuttle Radar Topography Mission, Rev. Geophys., 45, RG2004, https://doi.org/10.1029/2005RG000183, 2007.

Favier, L., Durand, G., Cornford, S., Gudmundsson, G., Gagliardini, O., Gillet-Chaulet, F., Zwinger, T., Payne, J., and LeBrocq, A.: Retreat of Pine Island Glacier controlled by marine ice-sheet instability, Nat. Clim. Change, 4, 117-121, https://doi.org/10.1038/nclimate2094, 2014.

Franco, B., Fettweis, X., Lang, C., and Erpicum, M.: Impact of spatial resolution on the modelling of the Greenland ice sheet surface mass balance between 1990-2010, using the regional climate model MAR, The Cryosphere, 6, 695-711, https://doi.org/10.5194/tc-6-695-2012, 2012.

Frey, H., Machguth, H., Huss, M., Huggel, C., Bajracharya, S., Bolch, T., Kulkarni, A., Linsbauer, A., Salzmann, N., and Stof- fel, M.: Estimating the volume of glaciers in the HimalayanKarakoram region using different methods, The Cryosphere, 8 , 2313-2333, https://doi.org/10.5194/tc-8-2313-2014, 2014.

Fürst, J., Goelzer, H., and Huybrechts, P.: Effect of higherorder stress gradients on the centennial mass evolution of the Greenland ice sheet, The Cryosphere, 7, 183-199, https://doi.org/10.5194/tc-7-183-2013, 2013.

Fürst, J., Durand, G., Gillet-Chaulet, F., Tavard, L., Rankl, M., Braun, M., and Gagliardini, O.: The safety band of Antarctic ice shelves, Nat. Clim. Change, 6, 479-482, https://doi.org/10.1038/nclimate2912, 2016.

Gagliardini, O. and Zwinger, T.: The ISMIp-HOM benchmark experiments performed using the Finite-Element code Elmer, The Cryosphere, 2, 67-76, https://doi.org/10.5194/tc-2-67-2008, 2008.

Gagliardini, O., Zwinger, T., Gillet-Chaulet, F., Durand, G., Favier, L., de Fleurian, B., Greve, R., Malinen, M., Martín, C., Råback, P., Ruokolainen, J., Sacchettini, M., Schäfer, M., Seddik, H., and Thies, J.: Capabilities and performance of Elmer/Ice, a newgeneration ice sheet model, Geophys. Model Dev., 6, 1299-1318, https://doi.org/10.5194/gmd-6-1299-2013, 2013.

Gantayat, P., Kulkarni, A., and Srinivasan, J.: Estimation of ice thickness using surface velocities and slope: case study at Gangotri Glacier, India, J. Glaciol., 60, 277-282, https://doi.org/10.3189/2014JoG13J078, 2014.

Gardelle, J., Berthier, E., and Arnaud, Y.: Impact of resolution and radar penetration on glacier elevation changes computed from DEM differencing, J. Glaciol., 58, 419-422, https://doi.org/10.3189/2012JoG11J175, 2012.

Gardelle, J., Berthier, E., Arnaud, Y., and Kääb, A.: Regionwide glacier mass balances over the Pamir-KarakoramHimalaya during 1999-2011, The Cryosphere, 7, 1263-1286, https://doi.org/10.5194/tc-7-1263-2013, 2013.

Gärtner-Roer, I., Naegeli, K., Huss, M., Knecht, T., Machguth, H., and Zemp, M.: A database of worldwide glacier thickness observations, Global Planet. Change, 122, 330-344, https://doi.org/10.1016/j.gloplacha.2014.09.003, 2014.

Gärtner-Roer, I., Andreassen, L., Bjerre, E., Farinotti, D., Fischer, A., Fischer, M., Helfricht, K., Huss, M., Knecht, T., Landmann, S. K. J., Li, I. L. H., Li, Z., Machguth, H., Naegeli, K., Navarro, F., Rabatel, A., Stentoft, P., and Zemp, M. (Eds.): WGMS (2016): Glacier Thickness Database 2.0., World Glacier Monitoring Service, Zurich, Switzerland, https://doi.org/10.5904/wgmsglathida-2016-07, 2016.

Geuzaine, C. and Remacle, J.: Gmsh: a three-dimensional finite element mesh generator with built-in pre- and post-processing facilities, Int. J. Numer. Meth. Eng., 79, 1309-1331, 2009.

Gilbert, J. and Lemaréchal, C.: Some numerical experiments with variable-storage quasi-Newton algorithms, Math. Program., 45 , 407-435, 1989.

Gillet-Chaulet, F., Gagliardini, O., Seddik, H., Nodet, M., Durand, G., Ritz, C., Zwinger, T., Greve, R., and Vaughan, D. Greenland ice sheet contribution to sea-level rise from a newgeneration ice-sheet model, The Cryosphere, 6, 1561-1576, https://doi.org/10.5194/tc-6-1561-2012, 2012.

Grabiec, M., Jania, J., Puczko, D., Kolondra, L., and Budzik, T.: Surface and bed morphology of Hansbreen, a tidewater glacier in Spitsbergen, Polish Polar Res., 33, 111-138, https://doi.org/10.2478/v10183-012-0010-7, 2012. 
Hindmarsh, R.: The role of membrane-like stresses in determining the stability and sensitivity of the Antarctic ice sheets: back pressure and grounding line motion, Philos. T. Roy. Soc. A, 364, 1733-1767, https://doi.org/10.1098/rsta.2006.1797, 2006.

Huss, M. and Farinotti, D.: Distributed ice thickness and volume of all glaciers around the globe, J. Geophys. Res., 117, F04010, https://doi.org/10.1029/2012JF002523, 2012.

Huss, M. and Hock, R.: A new model for global glacier change and sea-level rise, Front. Earth Sci., 3, 1261-1273, https://doi.org/10.3389/feart.2015.00054, 2015.

Hutter, K.: Theoretical glaciology. Material science of ice and the mechanics of glaciers and ice sheets, Publishing Company/Tokyo, Terra Scientific Publishing Company, Dordrecht, Boston, Tokyo, Japan, Hingham, 1983.

Ignatiuk, D., Piechota, A., Ciepły, M., and Luks, B.: Changes of altitudinal zones of Werenskioldbreen and Hansbreen in period 1990-2008, Svalbard, AIP Conf. Proc., 1618, 275-280, https://doi.org/10.1063/1.4897727, 2014.

Jakobsson, M., Mayer, L., Coakley, B., Dowdeswell, J., Forbes, S., Fridman, B., Hodnesdal, H., Noormets, R., Pedersen, R., Rebesco, M., Schenke, H., Zarayskaya, Y., Accettella, D., Armstrong, A., Anderson, R., Bienhoff, P., Camerlenghi, A., Church, I., Edwards, M., Gardner, J., Hall, J., Hell, B., Hestvik, O., Kristoffersen, Y., Marcussen, C., Mohammad, R., Mosher, D., Nghiem, S., Pedrosa, M., Travaglini, P., and Weatherall, P.: The International Bathymetric Chart of the Arctic Ocean (IBCAO) Version 3.0, Geophys. Res. Lett., 39, 112609, https://doi.org/10.1029/2012GL052219, 2012.

Jania, J., Mochnacki, D., and Gądek, B.: The thermal structure of Hansbreen, a tidewater glacier in southern Spitsbergen, Svalbard , Polar Res., 15, 53-66, 1996.

Joughin, I., Smith, B., Howat, I., Scambos, T., and Moon, T.: Greenland flow variability from ice-sheetwide velocity mapping, J. Glaciol., 56, 415-430, https://doi.org/10.3189/002214310792447734, 2010.

Kamb, B. and Echelmeyer, K.: Stress-Gradient Coupling Glacier Flow. 1. Longitudinal Averaging of the Influence of Ice Thickness and Surface Slope, J. Glaciol., 32, 267-284, 1986.

Korona, J., Berthier, E., Bernard, M., Rémy, F., and Thouvenot, E.: SPIRIT. \{SPOT\} 5 stereoscopic survey of Polar Ice: Reference Images and Topographies during the fourth International Polar Year (2007-2009), ISPRS J. Photogram. Remote Sens., 64, 204212, https://doi.org/10.1016/j.isprsjprs.2008.10.005, 2009.

Krieger, G., Zink, M., Bachmann, M., Bräutigam, B., Schulze, D., Martone, M., Rizzoli, P., Steinbrecher, U., Walter Antony, J., De Zan, F., Hajnsek, I., Papathanassiou, K., Kugler, F., Rodriguez Cassola, M., Younis, M., Baumgartner, S., LópezDekker, P., Prats, P., and Moreira, A.: TanDEM-X: A radar interferometer with two formation-flying satellites, Acta Astronaut., 89, 83-89, https://doi.org/10.1016/j.actaastro.2013.03.008, 2013

Lang, C., Fettweis, X., and Erpicum, M.: Future climate and surface mass balance of Svalbard glaciers in an RCP8.5 climate scenario: a study with the regional climate model MAR forced by MIROC5, The Cryosphere, 9, 945-956, https://doi.org/10.5194/tc-9-945-2015, 2015.

Lapazaran, J., Otero, J., Martín-Español, A., and Navarro, F.: On the errors involved in ice-thickness estimates I: ground- penetrating radar measurement errors, J. Glaciol., 62, 10081020, https://doi.org/10.1017/jog.2016.93, 2016.

Linsbauer, A., Paul, F., and Haeberli, W.: Modeling glacier thickness distribution and bed topography over entire mountain ranges with GlabTop: Application of a fast and robust approach, J. Geophys. Res., 117, f03007, https://doi.org/10.1029/2011JF002313, 2012.

Marzeion, B., Jarosch, A., and Hofer, M.: Past and future sealevel change from the surface mass balance of glaciers, The Cryosphere, 6, 1295-1322, https://doi.org/10.5194/tc-6-12952012, 2012.

Marzeion, B., Cogley, J., Richter, K., and Parkes, D.: Attribution of global glacier mass loss to anthropogenic and natural causes, Science, 345, 919-921, https://doi.org/10.1126/science.1254702, 2014.

McNabb, R., Hock, R., O’Neel, S., Rasmussen, L., Ahn, Y., Braun, M., Conway, H., Herreid, S., Joughin, I., Pfeffer, W., Smith, B. and Truffer, M.: Using surface velocities to calculate ice thickness and bed topography: a case study at Columbia Glacier, Alaska, USA, J. Glaciol., 58, 1151-1164, 2012.

Moholdt, G., Nuth, C., Hagen, J., and Kohler, J.: Recent elevation changes of Svalbard glaciers derived from ICESat laser altimetry, Remote Sens. Environ., 114, 2756-2767, https://doi.org/10.1016/j.rse.2010.06.008, 2010.

Möller, M., Obleitner, F., Reijmer, C., Pohjola, V., Głowacki, P., and Kohler, J.: Adjustment of regional climate model output for modeling the climatic mass balance of all glaciers on Svalbard, J. Geophys. Res.-Atmos., 121, 5411-5429, https://doi.org/10.1002/2015JD024380, 2016.

Moran, M., Greenfield, R., Arcone, S., and Delaney, A.: Delineation of a complexly dipping temperate glacier bed using short-pulse radar arrays, J. Glaciol., 46, 274-286, https://doi.org/10.3189/172756500781832882, 2000.

Morland, L.: Unconfined ice-shelf flow, in: Dynamics of the West Antarctic ice sheet, Kluwer Academic Publishers, Boston, Mass. Canada, Dordrecht, the Netherlands, Hingham, MA, 1986.

Morlighem, M., Rignot, E., Seroussi, H., Larour, E., Ben Dhia, H., and Aubry, D.: A mass conservation approach for mapping glacier ice thickness, Geophys. Res. Lett., 38, L19503, https://doi.org/10.1029/2011GL048659, 2011.

Morlighem, M., Rignot, E., Mouginot, J., Seroussi, H., and Larour, E.: Deeply incised submarine glacial valleys beneath the Greenland ice sheet, Nat. Geosci., 7, 418-422, https://doi.org/10.1038/ngeo2167, 2014.

Mosbeux, C., Gillet-Chaulet, F., and Gagliardini, O.: Comparison of adjoint and nudging methods to initialise ice sheet model basal conditions, Geosci. Model Dev., 9, 2549-2562, https://doi.org/10.5194/gmd-9-2549-2016, 2016.

Navarro, F., Martín-Español, A., Lapazaran, J., Grabiec, M., Otero, J., Vasilenko, E., and Puczko, D.: Ice Volume Estimates from Ground-Penetrating Radar Surveys, Wedel Jarlsberg Land Glaciers, Svalbard, Arct. Antarct. Alp. Res., 46, 394-406, https://doi.org/10.1657/1938-4246-46.2.394, 2014.

Norwegian Polar Institute: Terrengmodell Svalbard (S0 Terrengmodell; data set), Norwegian Polar Institute, https://doi.org/10.21334/npolar.2014.dce53a47. 2014.

Nuth, C. and Kääb, A.: Co-registration and bias corrections of satellite elevation data sets for quantifying glacier thickness change, 
The Cryosphere, 5, 271-290, https://doi.org/10.5194/tc-5-2712011, 2011.

Nuth, C., Kohler, J., König, M., von Deschwanden, A., Hagen, J., Kääb, A., Moholdt, G., and Pettersson, R.: Decadal changes from a multi-temporal glacier inventory of Svalbard, The Cryosphere, 7, 1603-1621, https://doi.org/10.5194/tc-7-1603-2013, 2013.

Ottesen, D., Dowdeswell, J., Landvik, J., and Mienert, J.: Dynamics of the Late Weichselian ice sheet on Svalbard inferred from high-resolution sea-floor morphology, Boreas, 36, 286306, https://doi.org/10.1111/j.1502-3885.2007.tb01251.x, 2007.

Paolo, F., Fricker, H., and Padman, L.: Volume loss from Antarctic ice shelves is accelerating, Science, 348, 327-331, https://doi.org/10.1126/science.aaa0940, 2015.

Paul, F., Bolch, T., Kääb, A., Nagler, T., Nuth, C., Scharrer, K., Shepherd, A., Strozzi, T., Ticconi, F., Bhambri, R., Berthier, E., Bevan, S., Gourmelen, N., Heid, T., Jeong, S., Kunz, M., L., T. R., Luckman, A., Merryman Boncori, J., Moholdt, G., Muir, A., Neelmeijer, J., Rankl, M., VanLooy, J., and Van Niel, T.: The glaciers climate change initiative: Methods for creating glacier area, elevation change and velocity products, Remote Sens. Environ., 162, 408-426, https://doi.org/10.1016/j.rse.2013.07.043, 2015

Pettersson, R., Christoffersen, P., Dowdeswell, J., Pohjola, V., Hubbard, A., and Strozzi, T.: Ice thickness and basal conditions of Vestfonna Ice Cap, Eastern Svalbard, Geograf. Ann. A, 93, 311322, https://doi.org/10.1111/j.1468-0459.2011.00438.x, 2011.

Pinglot, J., Pourchet, M., Lefauconnier, B., Hagen, J., Isaksson, E., Vaikmae, R., and Kamiyama, K.: Accumulation in Svalbard glaciers deduced from ice cores with nuclear tests and Chernobyl reference layers, Polar Res., 18, 315-321, https://doi.org/10.1111/j.1751-8369.1999.tb00309.x, 1999.

Pinglot, J., Hagen, J., Melvold, K., Eiken, T., and Vincent, C.: A mean net accumulation pattern derived from radioactive layers and radar soundings on Austfonna, Nordaustlandet, Svalbard, J. Glaciol., 47, 555-566, https://doi.org/10.3189/172756501781831800, 2001.

Pohjola, V., Christoffersen, P., Kolondra, L., Moore, J., Pettersson, R., Schäfer, M., Strozzi, T., and Reijmer, C.: Spatial distribution and change in the surface-velocity field of Vestfonna ice cap, Nordaustlandet, Svalbard, 1995-2010 using geodetic and satellite interferometry data, Geograf. Ann. A, 93, 323-335, https://doi.org/10.1111/j.1468-0459.2011.00441.x, 2011.

Radić, V. and Hock, R.: Regionally differentiated contribution of mountain glaciers and ice caps to future sea-level rise, Nat. Geosci., 4, 91-94, https://doi.org/10.1038/ngeo1052, 2011.

Radić, V., Bliss, A., Beedlow, A., Hock, R., and Cogley, E. M. J.: Regional and global projections of twenty-first century glacier mass changes in response to climate scenarios from global climate models, Clim. Dynam., 42, 37-58, https://doi.org/10.1007/s00382-013-1719-7, 2014.

Rankl, M. and Braun, M.: Glacier elevation and mass changes over the central Karakoram region estimated from TanDEM-X and SRTM/X-SAR digital elevation models, Ann. Glaciol., 51, 273 281, https://doi.org/10.3189/2016AoG71A024, 2016.

Rankl, M., Kienholz, C., and Braun, M.: Glacier changes in the Karakoram region mapped by multimission satellite imagery, The Cryosphere, 8, 977-989, https://doi.org/10.5194/tc-8-9772014, 2014.
Raup, B., Racoviteanu, A., Khalsa, S., Helm, C., Armstrong, R., and Arnaud, Y.: The GLIMS Geospatial Glacier Database: a New Tool for Studying Glacier Change, Global Planet. Change, 56, 101-110, https://doi.org/10.1016/j.gloplacha.2006.07.018, 2007.

Rignot, E. and Mouginot, J.: Ice flow in Greenland for the International Polar Year 2008-2009, Geophys. Res. Lett., 39, L11501, https://doi.org/10.1029/2012GL051634, 2012.

Rignot, E., Mouginot, J., and Scheuchl, B.: Ice Flow of the Antarctic Ice Sheet, Science, 333, 1427-1430, https://doi.org/10.1126/science.1208336, 2011.

Rosenau, R., Scheinert, M., and Dietrich, R.: A processing system to monitor Greenland outlet glacier velocity variations at decadal and seasonal time scales utilizing the Landsat imagery, Remote Sens. Environ., 169, 1-19, https://doi.org/10.1016/j.rse.2015.07.012, 2015.

Schoof, C.: Ice sheet grounding line dynamics: Steady states, stability, and hysteresis, J. Geophys. Res., 112, F03S28, https://doi.org/10.1029/2006JF000664, 2007.

Schoof, C.: Ice-sheet acceleration driven by melt supply variability, Nature, 468, 803-806, https://doi.org/10.1038/nature09618, 2010.

Schutz, B., Zwally, H., Shuman, C., Hancock, D., and DiMarzio, J.: Overview of the ICESat Mission, Geophys. Res. Lett., 32, L21S01, https://doi.org/10.1029/2005GL024009, 2005.

Schwaizer, G.: Performance assessment of the glacier ice velocity products for Greenland, and description of the evaluation methodology, Glaciers validation report, http://sen3app.fmi. fi/index.php?page $=$ Deliverables_\&style $=$ main $\& p=2$ (last access: 23 August 2017), 2016.

Seehaus, T., Marinsek, S., Helm, V., Skvarca, P., and Braun, M.: Changes in ice dynamics, elevation and mass discharge of Dinsmoor-Bombardier-Edgeworth glacier system, Antarctic Peninsula, Earth Planet. Sc. Lett., 427, 125-135, https://doi.org/10.1016/j.epsl.2015.06.047, 2015.

Seehaus, T., Marinsek, S., Skvarca, P., van Wessem, J., Reijmer, C., Seco, J., and Braun, M.: Dynamic Response of Sjögren Inlet Glaciers, Antarctic Peninsula, to Ice Shelf Breakup Derived from Multi-Mission Remote Sensing Time Series, Front. Earth Sci., 4, 1-13, https://doi.org/10.3389/feart.2016.00066, 2016.

Strozzi, T., Luckman, A., Murray, T., Wegmüller, U., and Werner, C. L.: Glacier motion estimation using SAR offsettracking procedures, IEEE T. Geosci. Remote, 40, 2384-2391, https://doi.org/10.1109/TGRS.2002.805079, 2002.

Tachikawa, T., Hato, M., Kaku, M., and Iwasaki, A.: The characteristics of ASTER GDEM version 2, in: International Geoscience and Remote Sensing Symposium Proceedings, 24-29 July 2011, Canvouver, BC, Canada https://doi.org/10.1109/IGARSS.2011.6050017, 2011.

van Pelt, W., Oerlemans, J., Reijmer, C., Pettersson, R., Pohjola, V., Isaksson, E., and Divine, D.: An iterative inverse method to estimate basal topography and initialize ice flow models, The Cryosphere, 7, 987-1006, https://doi.org/10.5194/tc-7-9872013, 2013.

Vijay, S. and Braun, M.: Elevation Change Rates of Glaciers in the Lahaul-Spiti (Western Himalaya, India) during 2000-2012 and 2012-2013, Remote Sensing, 8, 1038, https://doi.org/10.3390/rs8121038, 2016.

Zwally, H., Li, J., Brenner, A., Beckley, M., Cornejo, H., Dimarzio, J., Giovinetto, M., Neumann, T., Robbins, J., Saba, 
J., Yi, D., and Wang, W.: Greenland ice sheet mass balance: distribution of increased mass loss with climate warming; 2003-07 versus 1992-2002, J. Glaciol., 57, 88-102, https://doi.org/10.3189/002214311795306682, 2011.
Zwally, H., Li, J., Robbins, J., Saba, J., Yi, D., and Brenner, A.: Mass gains of the Antarctic ice sheet exceed losses, J. Glaciol. 61, 1019-1036, https://doi.org/10.3189/2015JoG15J071, 2015. 